\title{
Sustainable life support on Mars - the potential roles of cyanobacteria
}

\author{
Cyprien Verseux ${ }^{1,2}$, Mickael Baqué', Kirsi Lehto ${ }^{3}$, Jean-Pierre P. de Vera ${ }^{4}$, Lynn \\ J. Rothschild ${ }^{5}$ and Daniela Billi ${ }^{1}$ \\ ${ }^{1}$ Department of Biology, University of Rome Tor Vergata, Rome, Italy \\ e-mail: cyprien.verseux@gmail.com \\ ${ }^{2}$ NASA EAP Associate, NASA Ames Research Center, Moffett Field, California, USA \\ ${ }^{3}$ Department of Plant Physiology and Molecular Biology, University of Turku, Turku, Finland \\ ${ }^{4}$ German Aerospace Center (DLR), Institute of Planetary Research, Berlin, Germany \\ ${ }^{5}$ Earth Sciences Division, NASA Ames Research Center, Moffett Field, California, USA
}

\begin{abstract}
Even though technological advances could allow humans to reach Mars in the coming decades, launch costs prohibit the establishment of permanent manned outposts for which most consumables would be sent from Earth. This issue can be addressed by in situ resource utilization: producing part or all of these consumables on Mars, from local resources. Biological components are needed, among other reasons because various resources could be efficiently produced only by the use of biological systems. But most plants and microorganisms are unable to exploit Martian resources, and sending substrates from Earth to support their metabolism would strongly limit the cost-effectiveness and sustainability of their cultivation. However, resources needed to grow specific cyanobacteria are available on Mars due to their photosynthetic abilities, nitrogen-fixing activities and lithotrophic lifestyles. They could be used directly for various applications, including the production of food, fuel and oxygen, but also indirectly: products from their culture could support the growth of other organisms, opening the way to a wide range of life-support biological processes based on Martian resources. Here we give insights into how and why cyanobacteria could play a role in the development of self-sustainable manned outposts on Mars.

Received 24 March 2015, accepted 22 June 2015, first published online 3 August 2015
\end{abstract}

Key words: cyanobacteria, in situ resource utilization (ISRU), life-support systems, Mars exploration, space technologies, synthetic biology.

\section{Introduction}

Sending humans to Mars within a few decades is now a realistic goal (e.g., Baker \& Zubrin 1990; Horneck et al. 2006; Drake 2009; Zubrin \& Wagner 2011). However, even though leaving a footprint and planting a flag could be achieved with not much more than the current state-of-the-art of engineering, a definite pay-back is still in doubt. On the other hand, if a Mars mission can allow extensive human scientific activity and yield meaningful scientific data, the effort is justified. In such a case, scientists will need to spend a considerable period on site, and multiple short-term missions are not a viable option. Given the time, costs and challenges associated with the journey, long-term human bases will likely be needed.

But while the vision of long-term human presence on Mars is compelling, providing consumables to sustain crews is a challenge. Even though launch costs vary depending on mission scenarios and might be reduced in the coming decades, they have been estimated to be in the order of $\$ 300000 \mathrm{~kg}^{-1}$ (Massa et al. 2007). Sending from Earth all the needed resources does not seem financially sustainable. Should Mars colonization be consequently deemed too expensive to be realistic? Maybe not. There are alternatives.

One is recycling - using regenerative systems. Such systems should have biology-based components: various life-support functions can be provided by physicochemical processes, but some valuable products such as high-protein food cannot currently be produced by the latter (Drysdale et al. 2003; Montague et al. 2012). In addition, many components of physicochemical life-support systems are heavy, highly energyconsuming and/or require high temperatures. Even in the case where these are the backbones of life-support systems, biological modules could both complement them and provide safe redundancies. Consequently, various bioregenerative lifesupport systems (BLSS) are or have been under development for recycling food, water and gases both in space (e.g., Godia et al. 2002; Gitelson et al. 2003; Drysdale et al. 2004; Lobascio et al. 2007; Nelson et al. 2010; Giacomelli et al. 2012) and within lunar and Martian outposts (e.g., Gitelson 1992; Blüm et al. 1994; Tikhomirov et al. 2007; Nelson et al. 2010). This may sound promising: instead of sending resources in amounts almost proportional to the mission length, only a few weeks' worth of consumables would be sent and recycled. The issue is: $100 \%$ recycling efficiency cannot be reached and losses are unavoidable. For quantitative information regarding the theoretical recycling efficiencies of the Micro-Ecological Life Support System Alternative (MELiSSA), for example, see Poughon et al. (2009).

A regenerative system's running time without re-supply is consequently limited. It also cannot be expanded, as the 
mass of cycling components is, at a given time, at most equal to their initial mass. In addition to this, most current BLSS projects represent a large initial volume and mass, as well as a high power consumption. For instance, the mass of consumables needed to sustain a crew of 6 using the MELiSSA system has been assessed to be about 30 metric tons ( $\mathrm{mt}$ ), hygiene water not included, for a 1000-day mission (Langhoff et al. 2011). Re-supply is thus needed and the most advanced BLSS projects heavily depend on materials imported from Earth - although a theoretical physicochemical/biological resource production system relying on Martian resources has recently been patented (Cao et al. 2014). These projects are consequently not suitable for autonomous, long-term human bases on Mars: the mass problem is reduced, but not solved.

There is however a promising solution: producing resources from local materials. Like all human settlers of previous generations, the Martian pioneers must 'live off the land'. A critical question this fact raises is whether it is possible to feed biological systems with local resources. On the one hand, water $\left(\mathrm{H}_{2} \mathrm{O}\right)$, solar energy, carbon $(\mathrm{C})$, nitrogen $(\mathrm{N})$ and many other life-supporting nutrients are found on Mars (Meyer \& McKay 1989; Olsson-Francis \& Cockell 2010; Cockell 2014). But on the other hand, they cannot be directly exploited in the form in which they are found there by key organisms of current BLSS projects. This limitation may lead one to think that BLSS based on local resources are irrelevant for Mars exploration. What if, however, Martian resources could be exploited and processed into suitable forms by an additional biological module? What if there was a biological link between on-site resources and BLSS? This link might be created by cyanobacteria. All the inputs needed to sustain a diazotrophic (N-fixing), bioleaching cyanobacterium's metabolism could in theory be obtained from Mars's mineral resources, water, atmospheric gases and incident solar energy. Firstly, some (e. g., Anabaena spp. and various desert species) have the ability to extract and biologically fix nutrients from analogues of Martian rocks (Brown \& Sarkisova 2008; Olsson-Francis \& Cockell 2010). Owing to these abilities and to their useful products, cyanobacteria have already been suggested as a basis for creating planetary BLSS relying on local resources (Brown 2008a; Brown et al. 2008; Stanford-Brown 2011 iGEM team 2011). They are also able to fix $\mathrm{C}$ from carbon dioxide $\left(\mathrm{CO}_{2}\right)$ and some species can fix $\mathrm{N}$ from dinitrogen $\left(\mathrm{N}_{2}\right)$, both of which are found in the Martian atmosphere, leading to organic matter and dioxygen $\left(\mathrm{O}_{2}\right)$ production without dependency on carbohydrate feedstock. Some species are highly tolerant to extreme environments (e.g., Rothschild \& Mancinelli 2001); consequently their culture is less demanding in terms of hardware than that of more environmentally sensitive microbial species. Cyanobacteria could be used directly to produce resources such as food and $\mathrm{O}_{2}$, but products from their cultures could also be used to feed other living organisms, so opening the way to a wide range of life-support biological processes.

Cyanobacteria could thus provide the key link between BLSS and Martian resources, making the former sustainable and expandable in human bases on Mars. An artist's rendering of such a cyanobacterium-based BLSS ('CyBLiSS') is given in
Fig. 1. The present paper is not intended as a specific mission design, but rather as an overview of how and why cyanobacteria could be grown on Mars. We first outline their potential applications there. Then we discuss the associated challenges and possible ways of facing them. Finally, we outline the research efforts needed to design functional, cyanobacteriumbased BLSS for human outposts on Mars. A summary of this paper's contents is given in Fig. 2.

\section{Potential roles of cyanobacteria in Mars-specific BLSS}

\section{Feeding other microorganisms}

Heterotrophic microorganisms have been used throughout human history and would be highly useful on Mars. Potential applications include the production of drugs, food, biomaterials and various industrially useful chemicals, metal leaching and food processing for taste improvement (Cumbers \& Rothschild 2010; Langhoff et al. 2011; Montague et al. 2012; Menezes et al. 2014; Verseux et al. 2016). As most of these applications require relatively small culture volumes and no solar light, cultures could be performed under Earth-like conditions with reasonable costs. However, heterotrophic microorganisms rely on organic materials whose availability on Mars remain very poorly known and are not expected to be abundant there (Ming et al. 2014). Could the local resources be processed into suitable substrates by cyanobacteria? Related phenomena naturally occur on Earth, where cyanobacteria are known to support different heterotrophic communities. They can for instance be the earliest colonizers of desert habitats and allow the development of local ecosystems (including heterotrophic bacteria) through the production of organic compounds, $\mathrm{N}$ fixation and rock leaching (e.g., Eldridge \& Greene 1994; Danin et al. 1998; Herrera et al. 2009). In aquatic ecosystems as well, cross-feeding and metabolite exchange occur between cyanobacteria and heterotrophic microorganisms (see, for instance, Stevenson \& Waterbury 2006 and Beliaev et al. 2014).

The question of water is addressed in subsection 'Water'. Heterotrophic organisms also need, first of all, organic compounds as a source of $\mathrm{C}$ and energy. Lysed cyanobacterial biomass could be used as such (and as a source of other critical macronutrients such as hydrogen $[\mathrm{H}]$, oxygen [O], phosphorus [P] and sulphur [S]; for $\mathrm{N}$, see the following paragraph). Consistently, a filtrate of grinded Anabaena sp. PCC7120 (100 mg of dried biomass $\mathrm{ml}^{-1}$ before filtration) has been used as the only source of organic compounds and fixed $\mathrm{N}$ to grow Escherichia coli K-12 MG1655 in phosphate-buffered saline, reaching more than $10^{9}$ cells $\mathrm{ml}^{-1}$ within $24 \mathrm{~h}$ (Verseux, unpublished data). Note that these results are preliminary and that no optimization step (e.g., choice of a strain that can metabolize sucrose, alteration of culture conditions to modify cyanobacterial biomass's composition and/or more efficient extraction method) has yet been performed. Lysed cyanobacterial biomass has also been shown to be a suitable substrate for ethanol production in yeasts (Aikawa et al. 2013; Möllers et al. 2014). In lysogeny broth (LB), the most 


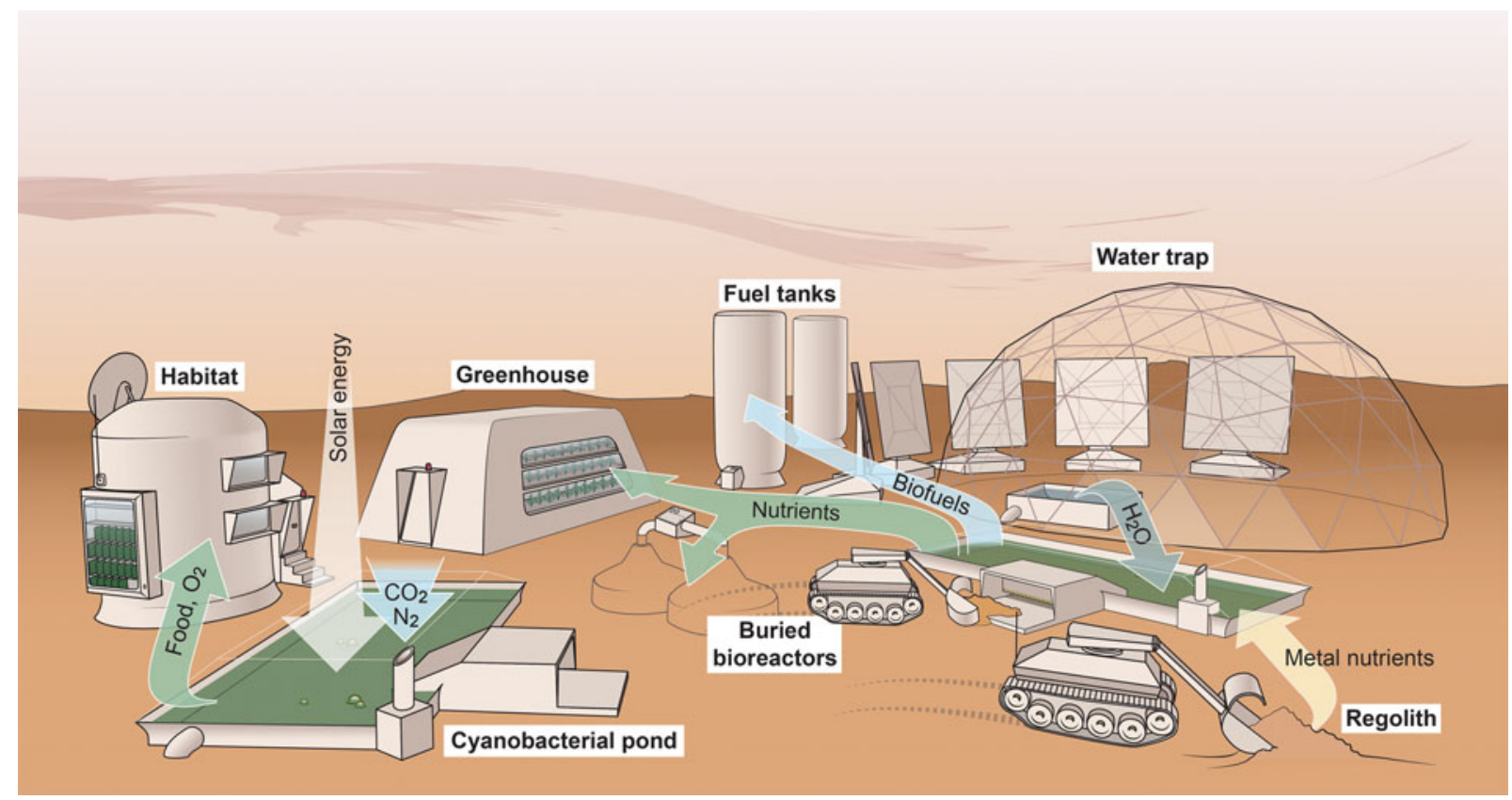

Fig. 1. Artist's rendering of a cyanobacterium-based biological life-support system on Mars. Figure design: Cyprien Verseux and Sean McMahon (Yale University). Layout: Sean McMahon.

common growth medium for heterotrophic bacteria in laboratories, the concentration of fermentable sugars and sugar equivalents (sugar phosphates, oligosaccharides, nucleotides, etc.) utilizable by $E$. coli is very low $(<100 \mu \mathrm{M})$, constraining bacteria to use amino acids as $\mathrm{C}$ sources (McFall \& Newman 1996; Sezonov et al. 2007). However, non-destructive ways of harvesting nutrients could lead to more efficient processes. Substrates could for instance be secreted. This solution has been investigated in Lynn Rothschild's laboratory (at NASA Ames Research Center, Moffett Field, CA) since the 2011 Stanford-Brown iGEM team engineered Anabaena sp. PCC7120 to secrete sucrose (Stanford-Brown 2011 iGEM team 2011), which was then used as a $C$ source to grow Bacillus subtilis (Ryan Kent et al., unpublished data). Prior to this, Synechococcus elongatus PCC7942 was engineered to produce and secrete either glucose and fructose, or lactate, then used as a substrate for E. coli (Niederholtmeyer et al. 2010). In this kind of system, a major limitation arises from low sugar yields, which are due to relatively low synthesis rates and to the consumption of sugars by the cyanobacteria themselves. Production rates could be increased by further genetic engineering to either increase synthesis or decrease processing of these products by the producer strains. External conditions could also be modified; for instance, osmotic stress induces sucrose accumulation in many cyanobacteria, especially when synthesis of other osmoprotectants is impaired (Miao et al. 2003).

Then, fixed $\mathrm{N}$ is needed. Heterotrophic bacteria can obtain $\mathrm{N}$ from various organic and inorganic sources such as single amino acids (e.g., Crawford et al. 1974) and amino acid chains (e.g., Hollibaugh \& Azam 1983; Coffin 1989), nucleic acids (Paul et al. 1989) and ammonium $\left(\mathrm{NH}_{4}^{+}\right)$. Diazotrophic cyanobacteria can produce all these compounds after $\mathrm{N}$ fixation and, here again, a simple way of making this $\mathrm{N}$ available to heterotrophic bacteria is to lyse cyanobacteria. $\mathrm{But} \mathrm{NH}_{4}^{+}$can be naturally released by some diazotrophic cyanobacteria, without cell lysis; for instance, extracellular $\mathrm{NH}_{4}^{+}$can reach several $\mathrm{mM}$ in cultures of Anabaena spp. (mutants or wild-type, depending on species) relying on atmospheric $\mathrm{N}_{2}$ as a sole $\mathrm{N}$ source (Spiller et al. 1986; Subramanian \& Shanmugasundaram 1986). $\mathrm{NH}_{4}^{+}$is the preferred $\mathrm{N}$ source for most microorganisms and becomes limiting at extremely low concentrations (e.g., below a few $\mu \mathrm{M}$ for E. coli; see Kim et al. 2012), several orders of magnitudes below the above-mentioned concentrations. Released $\mathrm{NH}_{4}^{+}$could be used for feeding not only heterotrophic microorganism, but also some phototrophic species of interest which cannot fix N. Within the MELiSSA loop (e.g., Godia et al. 2002), $\mathrm{NH}_{4}^{+}$ (there resulting from human and plant waste processing by thermophilic anaerobic bacteria) is converted into nitrates by nitrifying bacteria before being transferred to Arthrospira sp. cultures. Even though nitrate is considered the preferred $\mathrm{N}$ source for this species (as for most non-N fixing filamentous cyanobacteria), using $\mathrm{NH}_{4}^{+}$instead of nitrates has been shown not to reduce growth rates (Filali et al. 1997). A drawback is that $\mathrm{NH}_{4}^{+}$ becomes growth-limiting from relatively low concentrations (a few $\mathrm{mM}$ ) and should consequently, if limiting below these concentrations, be regularly (or continuously) added to the culture medium. Semi-separated cultures, where cyanobacteria's and heterotrophic microorganisms' culture vessels communicate through membranes that allow medium but not cell exchange, can also be considered. In such a case, extensive system characterization is needed to predict outputs, and processes could be optimized by improving the culture setup and by performing evolutionary selection of the co-culture to improve metabolic 


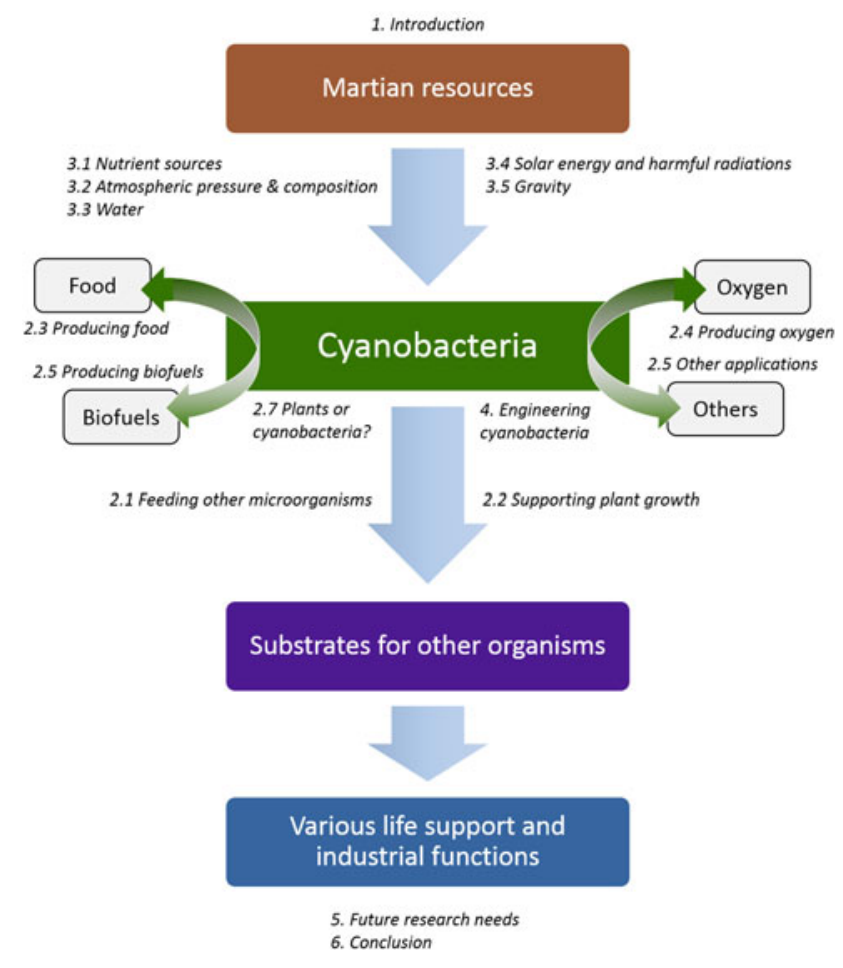

Fig. 2. Visual table of contents.

interactions. In any case, the rates of $\mathrm{NH}_{4}^{+}$release by strains of interest under Mars-like constraints, as well as the use of this $\mathrm{NH}_{4}^{+}$as an $\mathrm{N}$ source for non- $\mathrm{N}$ fixers, should be further investigated.

Many heterotrophic microorganisms also need $\mathrm{O}_{2}$. E. coli, for example, roughly needs $1 \mathrm{~g}$ of $\mathrm{O}_{2}$ per gram of dry weight (gdw) (Shiloach \& Fass 2005). $\mathrm{O}_{2}$ consumption and cell mass vary according to strain and cultures conditions, but this figure corresponds to approximately $1 \mathrm{~g}$ of $\mathrm{O}_{2} \mathrm{l}^{-1}$ to reach a culture of $2 \times 10^{9}$ cells $\mathrm{ml}^{-1}$. Cyanobacteria produce $\mathrm{O}_{2}$ through photosynthesis; details are given in subsection 'Producing oxygen'.

Finally, metals must be provided. Some (macronutrients) are needed in relatively large amounts; these are mostly potassium $(\mathrm{K})$, magnesium $(\mathrm{Mg})$ and iron $(\mathrm{Fe})$ and, for some species, sodium $(\mathrm{Na})$ and calcium $(\mathrm{Ca})$. Others (micronutrients) are needed in trace amounts by some microorganisms and include, for instance, chromium (Cr), manganese (Mn), nickel (Ni) and zinc ( $\mathrm{Zn}$ ) (Madigan et al. 2000). As an example, E. coli needs about $10^{8}$ atoms cell $^{-1}$ of $\mathrm{K}$ and $\mathrm{Mg} ; 10^{5}$ atoms cell $^{-1}$ of $\mathrm{Ca}$, $\mathrm{Zn}$ and $\mathrm{Fe}$; and $10^{4}$ atoms cell ${ }^{-1}$ of $\mathrm{Mn}$, molybdenum (Mo) and selenium (Se) (Finney \& O'Halloran 2003). All the needed elements seem to be present in Martian regolith (Cockell 2014), but some of them may be poorly available to most organisms with no leaching abilities. However, rock-dwelling cyanobacteria can extract metal nutrients from a wide range of rocks (see Olsson-Francis et al. 2012). Besides mobilizing them in their own cells, they help release them in the aqueous phase, increasing their concentration there (Olsson-Francis \& Cockell 2010; Olsson-Francis et al. 2012) and availability for nonleaching organisms. Anabaena cylindrica has for instance been shown to release elements including $\mathrm{K}, \mathrm{Mg}, \mathrm{Na}, \mathrm{Ca}$,
$\mathrm{Fe}, \mathrm{Mn}, \mathrm{Ni}$ and $\mathrm{Zn}$ from a Mars basalt analogue (Olsson-Francis \& Cockell 2010). The metals needed in highest amounts by $E$. coli, namely $\mathrm{K}$ and $\mathrm{Mg}$, reached concentrations of 125 and $55 \mu \mathrm{M}$, respectively, in large excess compared with

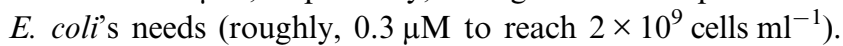
Even though lysing cyanobacterial biomass is the most straightforward option for transferring nutrients from cyanobateria to heterotrophic microorganisms, it may thus not be necessary. What solution minimizes the cost-to-productivity ratio is still to be determined.

\section{Supporting plant growth}

The majority of BLSS projects include plants for air and water regeneration and food production. Interestingly, all of the nutrients needed to grow plants $(\mathrm{C}, \mathrm{H}, \mathrm{N}, \mathrm{O}, \mathrm{P}, \mathrm{S}, \mathrm{K}, \mathrm{Mg}, \mathrm{Fe}, \mathrm{Na}$, $\mathrm{Ca}$ and micronutrients) seem to be present on Mars. Banin (1989) proposed using Martian regolith to grow plants and this approach is still under investigation (e.g., Silverstone et al. 2003, 2005; Nelson et al. 2008; Maggi \& Pallud 2010; Wamelink et al. 2014). However, even though Martian regolith is mostly basaltic and weathered basalt can yield extremely productive soils on Earth (Dahlgren et al. 1993), regolith will require physicochemical and/or biological treatment before it can be used as a growth substrate for plants. Besides excess salts, oxides and toxins, the main limiting factors are its low nutrient bioavailability and poor water-holding potential caused by low organic C contents (Maggi \& Pallud 2010; Cockell 2011). Enrichment of N, in particular, is critical: most plants cannot fix atmospheric N (a few, mainly legumes, benefit from symbiotic $\mathrm{N}$ fixation by specific bacteria harboured in their root tissues).

Some elements could be obtained by recycling human waste and inedible biomass from previous crops. However, relying solely on this would strongly limit sustainability and scalability of the system: without adding new components to the loop, the pool of supplies can only decrease over time. Again, inputs for plant cultivation should rather be provided from local resources. An interesting approach has been proposed in the context of lunar exploration. Following this approach, plant species which are tolerant to harsh growth conditions would be grown in local regolith, after inoculating seeds with a carefully chosen consortium of bioleaching bacteria to deliver nutrients to plant roots and to protect them against excessive accumulation of toxic elements. Once these 'first-generation plants' would have been grown, their biomass would be converted by microorganisms into a fertile protosoil used to support the growth of more demanding plants (Kozyrovska et al. 2006; Zaets et al. 2011). An alternative strategy could rely on cyanobacteria to process elements from rocks and fix N. Even though no plant cultures are currently produced using cyanobacteria as exclusive nutrient sources, the latter are used in agriculture to improve soil fertility, balance mineral nutrition and release biologically active substances that promote plant growth and increase plant resistance (Singh 2014). In the context of space exploration, cyanobacterial cultures have already been proposed as a way of releasing chemical elements from rocks to hydroponic solutions (Brown \& Sarkisova 2008). 
$\mathrm{N}$ fixed by cyanobacteria could also be used in hydroponic and/or soil-based systems. It could come from two main sources: from processed biomass containing for instance amino acid chains, and from released $\mathrm{NH}_{4}^{+}$.

Within the MELiSSA loop, $\mathrm{NH}_{4}^{+}$is converted into nitrates before being transferred to plants, but plants can also efficiently uptake $\mathrm{NH}_{4}^{+}$(see, e.g., Howitt \& Udvardi 2000). In theory, plant growth rates can even be higher with $\mathrm{NH}_{4}^{+}$than with nitrates due, first, to the energy needed to reduce nitrates to $\mathrm{NH}_{4}^{+}$ before its incorporation into organic compounds (Bloom et al. 1992) and, second, to a reduced need for photons, water and catalytic metal use per unit of $\mathrm{C}$ fixed when relying on $\mathrm{NH}_{4}^{+}$ (see Raven et al. 1992). However, experimental data often do not support this hypothesis (e.g., Raven et al. 1992). $\mathrm{NH}_{4}^{+}$induces toxicity at lower concentrations than nitrate, with a threshold which varies widely among species (Britto \& Kronzucker 2002). As a consequence, preference for $\mathrm{NH}_{4}^{+}$ over nitrate is species-dependent (Barker \& Mills 1980; Zhou et al. 2011). Even though $\mathrm{NH}_{4}^{+}$toxicity is not fully understood, it can presumably be explained in large part by the effect of the absorbed N's form on the uptake of other ions: $\mathrm{NH}_{4}^{+}$leads to higher anion uptake and lower cation uptake. It also affects $\mathrm{pH}$ : nitrate and $\mathrm{NH}_{4}^{+}$absorption induce, respectively, a release of hydroxyl ions $\left(\mathrm{HO}^{-}\right)$and a release of protons $\left(\mathrm{H}^{+}\right)$, and for some plants $\mathrm{NH}_{4}^{+}$'s negative effects can be reversed by buffering the medium (Britto \& Kronzucker 2002). Harmful effects could consequently be mitigated by controlling $\mathrm{pH}$ and adjusting the supply of other nutrients (Muhlestein et al. 1999), and by keeping $\mathrm{NH}_{4}^{+}$concentrations below toxic levels. Further studies could ascertain to what extent the growth-limiting effects of high $\mathrm{NH}_{4}^{+}$concentrations can be mitigated; more generally, work is needed to determine whether the benefits brought by nitrifying bacteria would justify the complexity and costs associated with their culture. Besides $\mathrm{NH}_{4}^{+}$, organic $\mathrm{N}$ from cyanobacterium biomass can be considered as an $\mathrm{N}$ source: plants can uptake amino acid chains (e.g., Lipson \& Näsholm 2001; Näsholm et al. 2009). Uptake of single amino acids and short peptides, and possibly di- and tripeptides, occurs via membrane transporters in root cells (Rentsch et al. 2007). Some plants can also uptake proteins after degradation by fungal symbionts (e.g., Bajwa et al. 1985 ) and at least some can do it without prior degradation by other organisms, either directly (presumably by endocytosis) or via the secretion of proteolytic enzymes (Godlewski \& Adamczyk 2007; Paungfoo-Lonhienne et al. 2008).

Symbioses between plants and diazotropic cyanobacteria naturally occur. The best-known instances involve aquatic ferns from the genus Azolla and their symbionts from the genus Anabaena (Peters \& Meeks 1989), and angiosperms from the genus Gunnera and their symbionts from the genus Nostoc (Bergman et al. 1992), but interactions naturally occur between cyanobacteria and representatives of most plant groups. Artificial symbioses between diazotrophic cyanobacteria and plants which normally do not harbour cyanobacterial symbionts, where the former provide fixed $\mathrm{N}$ to the latter, have also been successfully created with various plants including cereals (Gusev et al. 2002). In a hydroponic system, an Anabaena variabilis strain has even been shown to provide fixed $\mathrm{N}$ to wheat grown in an otherwise $\mathrm{N}$-free medium, yielding plant growth comparable with that of the control plants grown in a nitrate-containing medium (Spiller \& Gunasekaran 1990). Assessments of the cyanobacterium-to-plant biomass conversion efficiency, when all substrates besides $\mathrm{CO}_{2}$ and water come from cyanobacteria, require further experiments.

Even though experimental research is needed to quantify the nutrient composition of culture supernatants (with and without cell lysis), to determine the most efficient way of transferring nutrients from cyanobacterial cultures to other organisms and to get quantitative estimates of the system's requirements, cyanobacteria could thus be considered as a useful tool for processing local inorganic resources into a form which is available to other organisms (for a visual summary, see Fig. 3). But cyanobacteria could also be used directly for various applications. The most critical are outlined below.

\section{Producing food}

If all food came from Earth and assuming the easiest option of providing shelf-stable, prepackaged food similar to International Space Station's provisions, the amount to be sent would be about $1.8 \mathrm{~kg} \mathrm{day}^{-1}$ crewmember $^{-1}$ (Allen et al. 2003). Adding the needed vehicle and fuel weight to carry it and assuming a 10:1 vehicle-to-payload ratio (Hoffman \& Kaplan 1997), 1-year food supply for a crew of 6 would add more than $29 \mathrm{mt}$ to the initial mass of the transit vehicle. Worse, the load needed for a healthy diet would be much higher: even though convenient due to reduced need for storage facilities and contamination risks, a diet composed exclusively of this type of food would be nutritionally incomplete and thus not adequate in the long term. Frozen food could be seen as an interesting complement but would be extremely demanding in terms of storage facilities, could not be kept at commercial temperatures for more than about 1 year without losing palatability and would be unreliable due to potential freezing failure. Thus, even though current space food systems are relevant for short-term space missions and missions close to Earth (in low Earth orbit and possibly on the Moon), they must be developed further to meet the requirements of a manned mission to Mars (Perchonok et al. 2012). Establishing long-term human settlement on Mars seems unrealistic without local food production systems.

Growing plants might appear as an obvious option, even though creating an adequate environment on Mars would be particularly challenging at the first steps of colonization (details are given in the 'Plants or cyanobacteria?' section below). However, cyanobacteria could be an interesting alternative. Some species are edible, can be grown at a large scale and are expected (based on comparisons of metabolic pathways and human nutritional requirements) to be a nearly complete nutritional source, lacking only vitamin $\mathrm{C}$ and possibly essential oils (Way et al. 2011). Some species, notably from the genus Arthrospira, have consequently been studied as a potential food source in life-support systems (Hendrickx et al. 2006; Lehto et al. 2006). Arthrospira platensis is already used on Earth as a food supplement, and its nutritional value and 


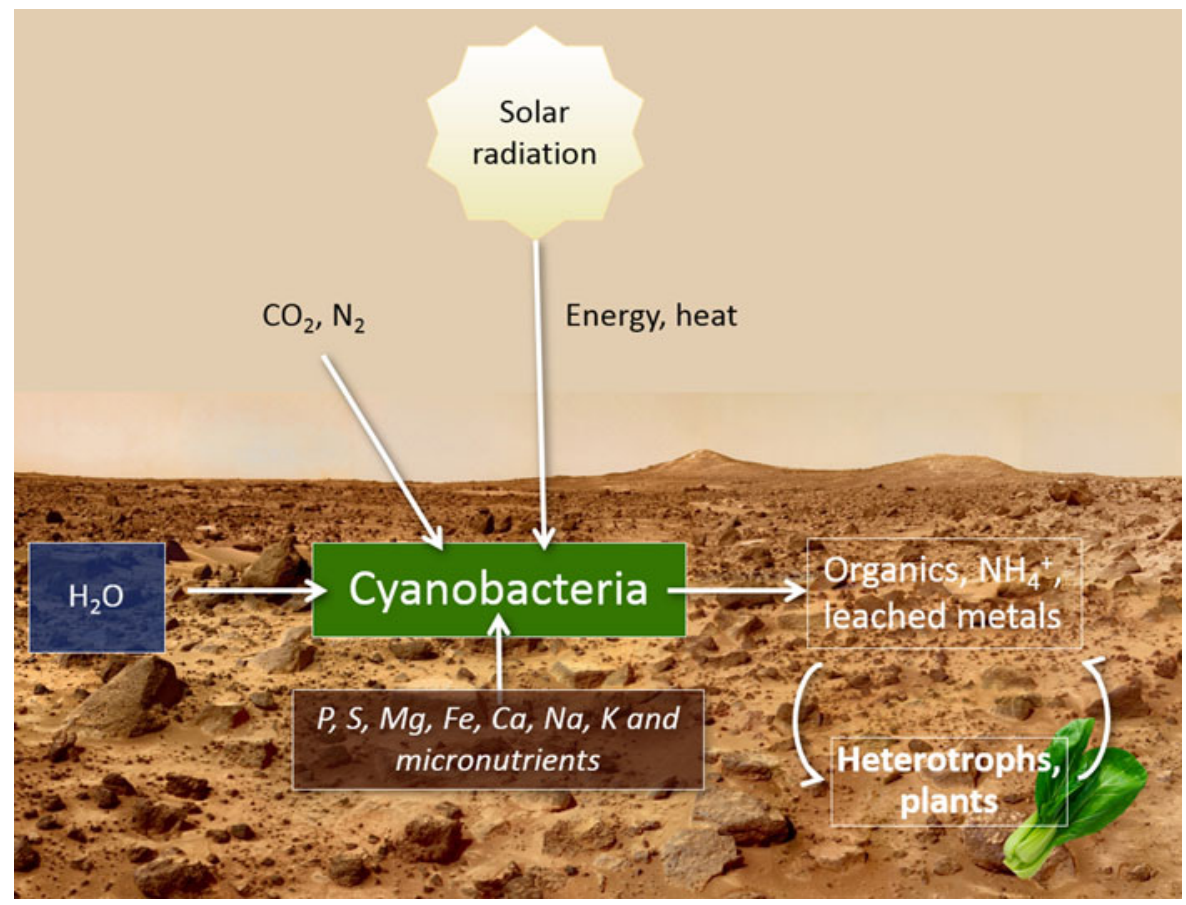

Fig. 3. Using cyanobacteria to process Martian resources into substrates for other organisms. In this scheme, cyanobacteria are fed with various nutrients obtained from the regolith, gaseous carbon and nitrogen from the atmosphere, energy from solar radiation, and water from various possible sources including ice caps, subsurface ice, atmosphere and hydrated minerals. Additional organic material, $\mathrm{CO}_{2}$ and water could be provided from metabolic and manufacturing waste resulting from human activity. Products from cyanobacterial cultures are then used as a substrate for heterotrophic microorganisms and plants.

lack of toxicity are well-characterized. Its dried biomass has been categorized 'Generally Recognized As Safe' (GRAS) for human consumption by the Food and Drug Administration (FDA) of the United States (FDA GRAS Notice No. GRN 000127). It has high protein contents (roughly, 50-70\% of the dry weight) and a high productivity: cultures in outdoor ponds under non-optimized conditions typically yield from 1 to $3 \times 10^{7} \mathrm{gdw} \mathrm{ha}^{-1} \mathrm{yr}^{-1}$ (Jiménez et al. 2003) and produce 20 times more proteins per hectare than soya's (Hendrickx et al. 2006; Henrikson 2009). Yields can be much enhanced in more controlled conditions. Cultures in photobioreactors can produce about $1 \mathrm{gdw}^{-1} \mathrm{day}^{-1}$ and, with such yields and assuming energetic contents of $3.75 \mathrm{kcal} \mathrm{gdw}^{-1}$ (Tokusoglu \& Unal 2003), $2000 \mathrm{kcal} \mathrm{day}^{-1}$ can be produced with about $0.53 \mathrm{~m}^{3}$. That being said, this figure is a very rough approximation of the actual needs: even though it covers mean caloric needs for a 30-50-year-old adult, it does not represent the amounts needed to cover nutritional needs. On the other hand, production rates can be further increased; for instance, a productivity of $16.8 \mathrm{gdw} \mathrm{m} \mathrm{m}^{-2} \mathrm{~h}^{-1}$ (there corresponding to $1.2 \mathrm{gdw}^{-1} \mathrm{~h}^{-1}$ ) has been attained for a short period of time using high $A$. platensis cell densities, a very short light path $(14 \mathrm{~mm})$, a very high photon flux $\left(8000 \mu \mathrm{mol} \mathrm{m}{ }^{-2} \mathrm{~s}^{-1}\right.$; about four times the solar flux on Earth when the Sun is directly overhead) and highly turbulent mixing (Qiang et al. 1998). Arthrospira spp. have health-promoting properties, including antiviral and antimutagenic functions which are especially relevant in Mars's highly irradiated environment (Lehto et al.
2007). They are also much more digestible than eukaryotic microalgae from the genus Chlorella, their main competitor as a photosynthetic microorganism-based food source, which have poorly digestible cellulose-containing cell walls.

However, Arthrospira spp. biomass currently cannot be used as a staple food: in addition to a taste that very few people would qualify as appealing, its carbohydrate-to-protein ratio is low, it contains very high levels of vitamin A, and it lacks vitamin $\mathrm{C}$ and possibly essential oils. Due to this nutritional imbalance, it is generally not recommended to consume more than $10 \mathrm{~g} \mathrm{day}^{-1}$. Cyanobacteria could be mixed with other microalgae and plants to optimize nutrient and fibre contents, as well as to diversify taste and texture, but limitations could also be addressed using synthetic biology (Way et al. 2011). Modifying the sugar, protein and lipid proportions, as well as introducing molecules that humans require (e.g., vitamin C) could be achieved using metabolic engineering and other genetic manipulations. Preliminary work has been done in this direction; for instance, mutant strains of $A$. platensis have been selected that are richer than the wild-type in compounds including essential amino acids, phycobiliproteins and carotenoids (Brown 2008b). Novel taste, smell and colour molecules could be produced by cells to increase palatability, attractiveness and meal diversity. It should also be taken into account that, depending on its adjusted pressure, Martian atmosphere can strongly affect the composition of cyanobacterial cultures: A. cylindrica cells grown under low pressure and high $\mathrm{CO}_{2}$ concentrations showed decreased protein contents 
and increased sugar contents compared with cells grown under ambient conditions (Lehto et al., unpublished data), shifting the protein/carbohydrate ratio closer to humans' needs.

Research has been extensively focused on Arthrospira spp., but other cyanobacterial species such as Nostoc commune, Nostoc flagelliforme and Anabaena spp. in symbiosis with Azolla spp. are traditionally consumed and more are edible. Arthrospira cultures require extensive nutrient supply (including fixed N), a high temperature with an optimum around $35^{\circ} \mathrm{C}$ and an alkaline $\mathrm{pH}$. Other species which are less demanding in terms of culture conditions might thus be more suitable on Mars and, even within the genus Arthrospira, species could be screened for the highest productivity under on-site constraints.

Cyanobacteria could also be used for food complementation without being directly eaten or even inactivated, as they can be engineered to secrete nutritional compounds (Way et al. 2011). As mentioned above, the possibility of engineering them to produce and secrete sugars has already been demonstrated (Niederholtmeyer et al. 2010; Stanford-Brown 2011 iGEM team 2011).

Finally, high-protein food could be suggested to come from animals. Granted, it is unrealistic to envision growing large species on Mars during its earliest colonization steps, due for instance to the need for an Earth-like environment, to low protein yields-to-allocated resources (area, water, vegetaloriginated proteins, working time, etc.) ratios and to the risk of pathogen transmission to humans. However, aquaculture of densely growing fish species (e.g., Tilapia spp.), crustaceans and shellfish may be considered (McKay et al. 1993) and cyanobacteria could be used for feeding them. Cyanobacteria are already used on Earth as a main food source for larvae of many species of fish, zooplankton (itself used for feeding fish larvae), crustaceans and shellfish (Pulz \& Gross 2004).

\section{Producing oxygen}

$\mathrm{O}_{2}$ will be one of the most critical resources in human bases on Mars, the most obvious reasons being human respiration and fuel oxidation. But it represents only $0.13 \%$ of Mars's atmosphere, against $21 \%$ of Earth's. Given the total pressures of both atmospheres, its partial pressure on Mars is more than 20000 times lower than on Earth. $\mathrm{O}_{2}$ thus needs to be either brought to Mars or produced there and, as for other resources, the second option is likely the most viable in the long term. On-site $\mathrm{O}_{2}$ production could be performed using physicochemical methods: by processing regolith, water and/ or atmospheric $\mathrm{CO}_{2}$ (e.g., by combining a $\mathrm{CO}_{2}$ scrubber, a Sabatier reactor and an electrolyser). However, cyanobacterium-based $\mathrm{O}_{2}$ production from $\mathrm{H}_{2} \mathrm{O}$ and $\mathrm{CO}_{2}$ could provide a safe redundancy (Sychev et al. 2003) and complement physicochemical methods. It could also be less energy demanding, and faster to set up and expand to face unexpected needs.

How much $\mathrm{O}_{2}$ is needed? Each crewmember consumes about $1 \mathrm{~kg}$ of $\mathrm{O}_{2}$ per day for respiration, assuming $2 \mathrm{~h}$ a day of intensive physical exercise (Horneck et al. 2003). If produced photosynthetically, this requires the fixation of more than 1.3 $\mathrm{kg}$ of $\mathrm{CO}_{2}$ a day, part of which could be provided, if useful, by recycling $\mathrm{CO}_{2}$ produced by the crew's metabolic activity (about $1 \mathrm{~kg} \mathrm{day}^{-1}$ crewmember $^{-1}$ ) and manufacturing activity in addition to using atmospheric $\mathrm{CO}_{2}$.

Cyanobacteria are very efficient $\mathrm{O}_{2}$ producers: whereas trees release about 2.5-11 t of $\mathrm{O}_{2} \mathrm{ha}^{-1} \mathrm{yr}^{-1}$, industrial cultivation in open ponds of Arthrospira species in Southeastern California release about $16.8 \mathrm{t}$ of $\mathrm{O}_{2} \mathrm{ha}^{-1} \mathrm{yr}^{-1}$. Cultures have been stated to be about 2.5 times more productive in the tropics (Henrikson 2009); under these conditions, about $80 \mathrm{~m}^{2}$ of culture per crewmember would be needed to cover human respiration needs. However, $\mathrm{O}_{2}$ production rates can be dramatically increased by photobioreactor-like culture systems which optimize for instance temperature, nutrient flow rates, cell density and illumination. Photosynthetic microorganisms from a eukaryotic microalgal genus, Chlorella, have been well-studied in the context of $\mathrm{O}_{2}$ production for life-support systems. For instance, an experimental system ('BIOS-I') was designed and tested in the 1960s where a man living in a sealed volume had his atmosphere and water regenerated by a Chlorella vulgaris culture. This work was preceded by experiments aimed at investigating the potential use of Chlorella spp. for air regeneration, performed by Y. Y. Shepelev and G. I. Meleshko at the Institute of Aerospace Medicine, Moscow, in 1960-1961 (Salisbury et al. 1997). In BIOS-I, $\mathrm{CO}_{2}$ excreted by the man and biogenous elements from his urine ( $\mathrm{N}, \mathrm{P}, \mathrm{S}$ and $\mathrm{K}$ ) were fed into the algal culture, which in turn produced $\mathrm{O}_{2}$ and purified water. Investigators showed that producing $500 \mathrm{~g}$ of dry algal biomass per person and per day was enough for water and air generation, and could be achieved in 20 litres only (with a $0.5 \mathrm{~cm}$ thick cultivation compartment between $8 \mathrm{~m}^{2}$ plane parallel walls to maximize light absorption), using one-side illumination with photosynthetically active radiation at $250-300 \mathrm{~W} \mathrm{~m}^{-2}$ (Kirensky et al. 1968 ; Gitelson 1992). The system was further developed, plants were added and various manned closure experiments were performed within 'BIOS-2' and 'BIOS-3', where Chlorella sp. was used to recycle part of the air (even though the Chlorella compartment was later replaced with additional plant compartments, mainly for food-related issues; see Salisbury et al. 1997).

Productivity will depend on conditions which will be provided on site. It should also be noted that the needed resources do not need to be dedicated to $\mathrm{O}_{2}$ production, as $\mathrm{O}_{2}$ will anyway be a side product of other processes relying on cyanobacteria and could be coupled with, for instance, food production.

\section{Producing biofuels}

If sending it from Earth, fuel would represent most of the load's mass to be sent from Earth and (for the journey back, assuming a return mission) from Mars. If it could be produced on-site, costs and technical challenges would be much reduced.

The next question concerns fuel-type. Dihydrogen $\left(\mathrm{H}_{2}\right)$ can be used for reducing local $\mathrm{CO}_{2}$ to hydrocarbons, and it has been proposed to bring some to Mars to produce methane $\left(\mathrm{CH}_{4}\right)$ and $\mathrm{H}_{2} \mathrm{O}$ (the latter can then be hydrolysed into $\mathrm{O}_{2}$ and $\mathrm{H}_{2}$ ). $\mathrm{H}_{2}$ could theoretically be directly used as a fuel: a mixture of liquid $\mathrm{H}_{2}$ and $\mathrm{O}_{2}$ have suitable propulsion performances. It is 
however much less attractive than $\mathrm{CH}_{4}$, among other reasons because of its very low density which induces a need for specialized combustion apparatus. In the Mars Direct plan (Baker \& Zubrin 1990; Zubrin et al. 1991; Zubrin \& Wagner 2011), 6 t of $\mathrm{H}_{2}$ would be used to generate enough $\mathrm{CH}_{4}$ and $\mathrm{O}_{2}$ to bring the return vehicle back to Earth and to power ground vehicles on the Martian surface. Mass could be further reduced if $\mathrm{H}_{2}$ was also obtained on Mars. Many cyanobacteria can produce it; among them, N-fixing heterocystous species such as Nostoc and Anabaena spp. are the most promising candidates. Their $\mathrm{H}_{2}$ production activity comes from their nitrogenases. These enzymes mainly catalyse the reduction of $\mathrm{N}_{2}$ to $\mathrm{NH}_{4}^{+}$but also, in the absence of $\mathrm{N}$, reduce $\mathrm{H}^{+}$to $\mathrm{H}_{2}$. On Earth, though, $\mathrm{H}_{2}$ photoproduction is currently too low for it to have practical applications. As an example, A. cylindrica grown in a standard medium for cyanobacteria (BG11), at ambient air composition and pressure, yields only about $0.2 \mu \mathrm{mol} \mathrm{H}_{2} \mathrm{mg} \mathrm{Chl} \mathrm{a}^{-1} \mathrm{~h}^{-1}$ (Murukesan et al. 2015). One of its main limitations is the inhibition by atmospheric $\mathrm{O}_{2}$ and $\mathrm{N}_{2}$ : nitrogenases are irreversibly inactivated by $\mathrm{O}_{2}$, while $\mathrm{N}_{2}$ strongly inhibits $\mathrm{H}^{+}$reduction. The high $\mathrm{CO}_{2}$, low $\mathrm{O}_{2}$ and $\mathrm{N}_{2}$ composition of the Martian atmosphere could thus be an advantage here. Consistently, yields above $20 \mathrm{ml} \mathrm{l}^{-1} \mathrm{~h}^{-1}$ (about $0.8 \mathrm{mmol}^{-1} \mathrm{~h}^{-1}$ ) were obtained with concentrated cultures of about $50 \mathrm{mg} \mathrm{Chl} \mathrm{a}{ }^{-1}$ of $A$. variabilis (so, roughly, 16 $\mu \mathrm{mol} \mathrm{H}_{2} \mathrm{mg} \mathrm{Chl} \mathrm{a}^{-1} \mathrm{~h}^{-1}$ ) under a 99\% argon (Ar), $1 \% \mathrm{CO}_{2}$ atmosphere (Liu et al. 2006). Recently, levels of about $25 \mu \mathrm{mol} \mathrm{mg}$ $\mathrm{Chl} \mathrm{a}^{-1} \mathrm{~h}^{-1}$ were also reached with $A$. cylindrica cultures under high $\mathrm{CO}_{2}$ /low $\mathrm{N}$ conditions (Murukesan et al. 2015). With a concentration of $50 \mathrm{mg} \mathrm{Chl} \mathrm{a} \mathrm{ml} l^{-1}$, these rates could lead to $1.5 \mathrm{mmol}^{-1} \mathrm{~h}^{-1}$ (about $35 \mathrm{ml} \mathrm{l}^{-1} \mathrm{~h}^{-1}$ at room temperature, with $30 \mu \mathrm{mol} \mathrm{mg} \mathrm{Chl} \mathrm{a} \mathrm{a}^{-1} \mathrm{~h}^{-1}$ ) of $\mathrm{H}_{2}$. Producing $6 \mathrm{t}$ of $\mathrm{H}_{2}$ would then require about $228 \mathrm{~m}^{3} \mathrm{yr}$. It corresponds, for example, to 22 days in a culture system the size of 3 m-deep Olympic swimming pool, or to 2 years and 4 months in $100 \mathrm{~m}^{3}$, assuming yields can be maintained at this scale. But these figures are very rough approximations: rates that would effectively be obtained on Mars depend on the mission scenario and technology choices for culture systems. Finally, current productivity is still far from its maximum, and increases are regularly obtained by culture conditions' optimization and metabolic engineering.

Leaving $\mathrm{H}_{2}$ aside, cyanobacteria can generate various biofuel precursors and components including alkanes, ethylene, hydrogen peroxide $\left(\mathrm{H}_{2} \mathrm{O}_{2}\right.$; which can be used as a monopropellant) and lipids, without relying on organic precursors (see, for instance, Quintana et al. 2011). They could also provide organic substrates for production of biofuel precursors by other organisms, particularly relevant on Mars where importing substrates from Earth would be impractical. For instance, as mentioned above, lysed cyanobacterial biomass has been used as a fermentation substrate for ethanol production in yeasts (Aikawa et al. 2013; Möllers et al. 2014). However, genetic engineering could remove the need for other organisms even for production of biofuel precursors which are not naturally produced by cyanobacteria in adequately large amounts - if at all. For instance, some cyanobacteria have been engineered to produce ethanol. Whereas yeasts rely on a sugar-based pathway and thus on the availability of agricultural substrates, engineered cyanobacteria produced it directly from $\mathrm{CO}_{2}$ and solar energy, following a much simpler process where pyruvate is first converted to acetaldehyde by a pyruvate decarboxylase and then to alcohol by an alcohol dehydrogenase (Deng \& Coleman 1999; Dalton \& Roberto 2008; Dexter \& Fu 2009). Generally speaking, a lot of work has been done to engineer new biofuel (or biofuel precursor) production pathways - or to improve existing ones - in cyanobacteria (see, e.g., Ducat et al. 2011). There is still much room for improvement, especially under Mars-like conditions.

Thus, even though extensive development and optimization is needed, cyanobacterium-based biotechnologies could represent original contributions to the production of rocket fuel for the return flight, for powering surface vehicles and, more generally, for powering equipment that can be operated by combustion engines.

\section{Other applications}

Various other applications involving cyanobacteria have been proposed for human outposts on Mars. One, for instance, is biomining. Microorganisms are used on Earth to extract metals of industrial interest (e.g., copper and gold) from rocks, and their use on Mars to mine basalt and potential ores has been suggested (Cockell 2010, 2011; Navarrete et al. 2012). Cyanobacteria are known to leach a wide range of rock types, including terrestrial volcanic rocks with compositions similar to Mars's regolith (Brown \& Sarkisova 2008; Olsson-Francis \& Cockell 2010; Olsson-Francis et al. 2012). The use of cyanobacteria, possibly engineered to increase their ability to dissolve rocks and harvest specific elements (Cockell 2011), can thus be considered for simple bioleaching processes that would not rely on imported $\mathrm{C}$ sources (needed for heterotrophic microorganisms) or toxic elements such as cyanide (used in non-biological leaching processes). Extracted elements could be used within a wide range of chemical and manufacturing processes such as, for instance, $\mathrm{CO}_{2}$ cracking, electroplating, production of alloys and manufacturing of solar cells (Dalton \& Roberto 2008; Cockell 2011).

Cyanobacteria have also been suggested for controlling Mars's surface dust, through the production of biological crusts, in enclosed structures such as greenhouses and habitats (Liu et al. 2008). Indeed, some can grow and form biofilms within the interstices of desert minerals and produce extracellular polysaccharides that bind the particles together, preventing windinduced dust release. Such crusts could also be used as an air filter to remove dust from the atmosphere (Cockell 2010). Then, the use of dehydrated Chroococcidiopsis cells as a gene repository for on-site molecular biology has been suggested (Billi et al. 2013), as they can preserve plasmids during long-term desiccation (Billi 2012) and presumably repair them when damaged. Cyanobacteria could also be used to process human waste products and recycle their organic $\mathrm{C}$, water, nitrates and mineral nutrients. Cultures could be used directly (Filali et al. 1997; Godia et al. 2002; Lehto et al. 2006; Yang et al. 2008) but also indirectly; for instance, $\mathrm{H}_{2} \mathrm{O}_{2}$ generated from cyanobacterium-produced $\mathrm{O}_{2}$ and $\mathrm{H}_{2} \mathrm{O}$ could be used to oxidize 
human wastes following a physicochemical process developed by researchers of the Institute of Biophysics of the Siberian Branch of the Russian Academy of Sciences (Kudenko et al. 2000); nutrients could then be recycled in cyanobacterial cultures (Tikhomirov et al. 2007). Cyanobacteria have also been suggested for the production, beyond Earth, of various chemicals including nutritional molecules, drugs, bioplastics and cellulosic building materials (Way et al. 2011; Menezes et al. 2014).

Finally, the ability of cyanobacteria to produce organic material from Martian resources, coupled to our increasing abilities in metabolic engineering, make it possible to consider many other applications ranging from performing basic lifesupport functions to generating comfort products.

\section{Plants or cyanobacteria?}

Assuming that both plants and cyanobacteria can be grown on Mars, some functions such as food and $\mathrm{O}_{2}$ production could be performed by either or both of them. For these functions, plants are the most commonly proposed photosynthetic organisms. This choice, however, is mostly due to our historical reliance on - and experience with - them: they have been a highly available food source throughout most of human history. Matters need to be reconsidered where environmental conditions, resources and other constraints are different.

Photosynthetic microorganisms are more efficient, on a volume basis, at capturing solar energy than plants. Their culture in photobioreactors could yield much more biomass (especially proteins) and $\mathrm{O}_{2}$ for a given volume and light intensity than greenhouse-type cultures of staple edible plants (Dismukes et al. 2008; Way et al. 2011; Wang et al. 2012). This is critical where resources are scarce and cultivation areas are highly controlled. Moreover, a considerable part of plant biomass (e.g., roots or stems, depending on species) is inedible and hard to recycle: plant cell walls are among the least degradable polymers in BLSS (Hendrickx \& Mergeay 2007).

Plants are also much more demanding in terms of environmental conditions. For instance, they are harmed by anoxia (roughly, a partial pressure of $\mathrm{O}_{2}$ of at least $50 \mathrm{hPa}$ is needed for proper development, mainly for non-photosynthetic tissues; see Thomas et al. 2005) and high concentrations of $\mathrm{CO}_{2}$ (negative effects have been observed in some plants above $4 \mathrm{hPa}$ [Wheeler 2004], while the partial pressure of $\mathrm{CO}_{2}$ $\left[\mathrm{pCO}_{2}\right.$ ] on Mars is above $6 \mathrm{hPa}$ ). Photosynthetic cultures on Mars, be they vegetal or bacterial, will have to be protected from biocidal environmental conditions. The needed level of protection - and the associated costs - will depend on the ability of cultured organisms to withstand these conditions, and many cyanobacteria are much more resistant than staple plants to the Martian surface's environmental stressors. They thrive in the most extreme habitable conditions on Earth, such as in dry deserts and ice lakes of Antarctica, and within ices of high Arctic seas (Wierzchos et al. 2006; Scalzi et al. 2012). Some have an outstanding resistance to environmental factors occurring on Mars's surfaces, including ultraviolet (UV) and ionizing radiation (see, for instance, Billi et al. 2013 and Thomas et al. 2006) and can survive in space when protected from UV radiation (Olsson-Francis et al. 2010).

In habitable compartments, gas consumed and produced by crewmembers must be balanced with gas consumed and produced by an atmosphere regenerating system. Since $\mathrm{CO}_{2}$ will be available in the atmosphere and since both $\mathrm{CO}_{2}$ and $\mathrm{O}_{2}$ will be generated as by-products of other processes, this system could be more flexible on Mars than in places where simple closed systems would be used: losses could be compensated and excess vented out. However, extensive control of the atmospheric balance would both increase safety and reduce resource consumption. By adjusting culture conditions, controlling cultures' assimilation quotient $\left(\mathrm{CO}_{2}\right.$ consumed $/ \mathrm{O}_{2}$ produced) to match humans' respiratory quotient $\left(\mathrm{CO}_{2}\right.$ produced $/ \mathrm{O}_{2}$ consumed) is much easier with cyanobacteria than with plants, making the atmospheric $\mathrm{O}_{2} / \mathrm{CO}_{2}$ balance much more manageable with the former (Averner et al. 1984; Horneck et al. 2003).

As crewmembers should be available for research and colony settlement and maintenance, time spent on culture management will have to be kept to a minimum. Culturing plants requires significant manpower; within Biosphere 2, for instance, agricultural and food-related tasks took about $45 \%$ of crew time (Silverstone \& Nelson 1996). In this framework, automation should be extensive. Cyanobacterial cultures are much more suitable for automation than plants' due to their culture homogeneity, growth in liquid medium and lack of inedible parts that should be sorted out. They are also much more manageable; culture parameters could be more easily adjusted to cover human needs, with a safety margin but without excess. Outputs could thus be much more controllable and predictable.

The time needed to establish cultures also matters. Even though shelf-stable food can be sent to sustain crews before cultures are first set up, it is important to be able to re-establish cultures in case of accidental loss - likely enough, and something with catastrophic consequences if not rapidly fixed. Being able to quickly extend cultures to cover unexpected needs (e.g., to compensate an $\mathrm{O}_{2}$ loss) can also be critical. Even though some plants can be grown faster, staple crops can take 3-4 months to mature even under favourable conditions (Drysdale et al. 2003). On the other hand, microbial cultures can be quickly expanded and re-deployed from very small amounts.

Finally, cyanobacteria are much easier to engineer than plants due to their rapid division times, compatibility to transformation, unicellularity and relatively simple genetic background (Koksharova \& Wolk 2002; Way et al. 2011; Berla et al. 2013). They could therefore be much more easily modified for new functions and adaptation to Martian conditions (see section 'Engineering cyanobacteria' below).

It should however be noted that plants have some advantages over cyanobacteria: they could provide tasty and carbohydrate-rich comfort food, and have beneficial psychological impacts on crewmembers (Allen 1991). Establishing small-scale cultures is not obviously unrealistic, especially if nutrients are provided from local resources as described above. 
Besides plants, one may wonder why the present paper focuses on cyanobacteria rather than eukaryotic microalgae, which could also perform some of the functions described above. Reasons include cyanobacteria's overall better abilities to use Martian resources (e.g., by $\mathrm{N}$ fixation and regolith leaching) and to withstand Martian conditions, the higher digestibility of their edible species and their higher growth and photosynthetic rates. They are also more suitable for genetic engineering, in part due to current transformation systems which are much simpler and well developed for cyanobacteria than for eukaryotic microalgae (Wang et al. 2012; Wijffels et al. 2013).

What about non-photosynthetic (chemotrophic) microorganisms? Heterotrophs may be useful on Mars, but not as primary producers (see subsection 'Feeding other microorganisms'). Resources needed to feed the metabolism of some chemoautotrophs, on the other hand, may be found on Mars; for example, reduced iron could be used as an energy source by iron-oxidizing bacteria (Nixon et al. 2013). Chemoautotrophs could thus be considered for some applications, such as the extraction of industrially useful minerals (Cockell 2010, 2011). However, none has the versatility of cyanobacteria to be the basis for BLSS: none combines, for instance, high $\mathrm{N}$ fixation rates, high growth rates, ability to rely exclusively on Martian resources, $\mathrm{O}_{2}$ production, $\mathrm{H}_{2}$ production, amenability to genetic manipulation and edible biomass.

\section{Growing cyanobacteria on Mars}

All organisms we currently know have evolved on Earth and none of them would be able to grow efficiently on the Martian surface. Cyanobacteria must be provided with shielding and an environment suitable for metabolism and growth. Elaborated hardware systems providing Earth-like conditions have been proposed but they rely on complex technology and require accurate control of all the process parameters (e.g., gases, temperatures and pressures in each compartment), are very demanding in terms of construction materials and energy consumption, need to be constructed on Earth, are very massive and expensive to carry to Mars, and can consequently be applied to small-scale cultures only. In order to be costeffective and reliable, culture hardware for large-scale, longterm, sustainable BLSS on Mars should be much simpler.

Fortunately, reproducing Earth-like conditions is not needed: cyanobacteria can grow under conditions which are much closer to Mars's. In addition, most inputs - if not all needed for growing cyanobacteria can be found on-site. An adequate culture system could thus provide a set of parameters (radiation shielding, atmospheric composition and pressure, gravity, nutrient supply, etc.) resulting from a compromise between (i) efficient support to growth and metabolism, and (ii) system feasibility and substrate availability on Mars's surface.

This culture system should be able to resist an inside/outside pressure difference, fine dust, large temperature gradients and strong radiation fluxes. Whatever its final design, efforts should be made to keep its weight, cost and energy consumption as low as reasonably possible given the other requirements. Ideally, the design should allow manufacturing from on-site compounds (e.g., regolith-based materials for radiation shielding, glass manufactured using silicon dioxide from Martian soil, and metallic parts derived from metal oxides mined in the regolith), assuming that equipment needed for processing is available on site. The potential of ultimately creating many of these facilities with local resources is currently being explored in Lynn Rothschild's laboratory.

\section{Nutrient sources}

Most elements needed for feeding plants and microorganisms can be found in Martian regolith.

Data on the composition of Martian soils and rocks have been obtained from analyses of the SNC (Shergottites, Nakhlites, Chassignites) group of meteorites (McSween 1994), the Viking (Clark et al. 1982), Pathfinder (Rieder 1997) and Phoenix (Hecht et al. 2009) landers, the Spirit rover (Morris et al. 2004), instruments operated from orbiters - noteworthy the Thermal Emission Spectrometer on Mars Global Surveyor (see Christensen et al. 2001), the Gamma Ray Spectrometer on Mars Odyssey (Boynton et al. 2007) and the Compact Reconnaissance Imaging Spectrometer for Mars (CRISM) on the Mars Reconnaissance Orbiter (Mustard et al. 2008) - and, recently, using X-ray spectrometers aboard the Opportunity and Curiosity rovers. In particular, the latter two have allowed detailed mineral compositions to be deduced at multiple sites in the Endeavour crater (Arvidson et al. 2014) and Gale crater (Grotzinger et al. 2014; McLennan et al. 2014; Ming et al. 2014; Vaniman et al. 2014). On Earth, basalt is the dominant rock type on the surface. It harbours much of the biosphere and, as an abundant source of redox couples and macronutrients, provides an efficient support to microbial life (for a review in the context of the search for life on Mars, see McMahon et al. 2013). Martian regolith is also in large part composed of basaltic minerals; more generally, Mars's surface seems to be mostly basaltic (McSween et al. 2009; Taylor \& McLennan 2009). All basic elements needed for cyanobacteria and other organisms (C, H, O, N, P, S, K, Mg, Na, Ca, Fe), as well as other elements needed in smaller amounts $(\mathrm{Mn}, \mathrm{Cr}, \mathrm{Ni}$, $\mathrm{Mo}, \mathrm{Cu}, \mathrm{Zn}$, etc.), have been detected there.

The most convenient sources of $\mathrm{C}$ and $\mathrm{N}$ will probably be atmospheric $\mathrm{CO}_{2}$ and $\mathrm{N}_{2}$ (see 'Atmospheric pressure and composition' section below). Additional $\mathrm{C}$ can be found in the $\mathrm{CO}_{2}$ ice caps, in the surface and subsurface regolith due to exchange with the atmosphere, and possibly in reservoirs formed when the atmosphere was thicker (Kurahashi-Nakamura \& Tajika 2006). It has also been suggested that fixed N, derived from Mars's atmospheric $\mathrm{N}_{2}$, may be buried in the regolith (Mancinelli \& Banin 2003; Boxe et al. 2012). Consistent with this, N-bearing compounds have been detected there (Ming et al. 2014). However, the exact nature and bioavailability of these compounds has not yet been determined.

Thus, all elements needed to support life seem to be present in Mars's rocks (Cockell 2014) and atmosphere. These nutrients can be directly made available to cyanobacteria, as multiple species thrive in a lithotrophic lifestyle, extracting all 
their needed mineral nutrients from rocky substrates (including basalt) and obtaining their whole $\mathrm{N}$ and $\mathrm{C}$ supply via photosynthesis and biological $\mathrm{N}$ fixation. Accordingly, some strains (e.g., A. cylindrica) have been grown in distilled water containing only powdered Mars basalt analogues (experiments were performed under terrestrial atmosphere; considerations on what atmospheric conditions are suitable are given in the 'Atmospheric pressure and composition' section below). Non-N fixing cyanobacteria could also grow when $\mathrm{NaNO}_{2}$ was added. On Mars, fixed $\mathrm{N}$ could come from $\mathrm{N}$ fixers (see above sections), while the possibility that nitrate beds are present cannot be ruled out. Supplementing the media with a sulphate source, $\left(\mathrm{NH}_{4}\right)_{2} \mathrm{SO}_{4}$, had a positive impact on some of the tested species. The authors suggested that, on Mars, gypsum $\left(\mathrm{NaSO}_{4} \cdot 2 \mathrm{H}_{2} \mathrm{O}\right)$ could be used as such a supplement (Olsson-Francis \& Cockell 2010). Gypsum dunes have indeed been found in the northern polar region of Mars by the OMEGA instrument on ESA's Mars Express orbiter (Langevin et al. 2005) and the CRISM and High Resolution Imaging Science Experiment instruments on NASA's Mars Reconnaissance Orbiter (Roach et al. 2007), and later confirmed by the rover Opportunity (Squyres et al. 2012). Other studies showed that the growth of several siderophilic cyanobacterial species isolated from iron-depositing hot springs in Yellowstone National Park was stimulated by the presence of Martian soil analogues in culture media (Brown \& Sarkisova 2008) and that Nostoc sp. HK-01 could grow on a Mars regolith stimulant for at least 140 days, without other nutrient source besides atmospheric gas (Arai et al. 2008). Other cyanobacteria have been grown using other Martian soil analogues as substrates, in distilled water or spread on gelified water plates. DLR's P-MRS and S-MRS simulants (Böttger et al. 2012), and NASA JSC's Mars-1A simulant (Allen et al. 1997), for instance, efficiently supported the growth of Matteia sp. and Anabaena sp. PCC7120 (see Fig. 4), respectively (Verseux et al., unpublished data). The need for providing regolith might be an issue for automation. However, using drilling photobioreactors that extract raw materials from the surface and directly bring them to cultures has been suggested (Cumbers \& Rothschild 2010) and technologies have been designed to excavate large amounts of regolith with minimal weight and time (see, e.g., Mueller \& Van Susante 2011).

Thus, even though it might be relevant to adequately mix rock types to have all nutrients in appropriate proportions and suitable $\mathrm{pH}$, and even though some salts, oxides and toxins might need to be removed, all nutrients and micronutrients needed to support cyanobacterial metabolism seem to be present on Mars. Additional nutrients could come from human waste. If some micronutrients (e.g., some cofactors) could not be mined or produced on site, bringing them from Earth would add a negligible mass to the initial payload as they are needed in trace amounts only. Methods for physicochemical preprocessing of Martian regolith and atmosphere (to generate, for instance, a broth of pre-leached regolith and nitric acid in which $\mathrm{CO}_{2}$ is bubbled; see Cao et al. 2014) could be considered, if the increased productivity outweighed the increased running cost and complexity.

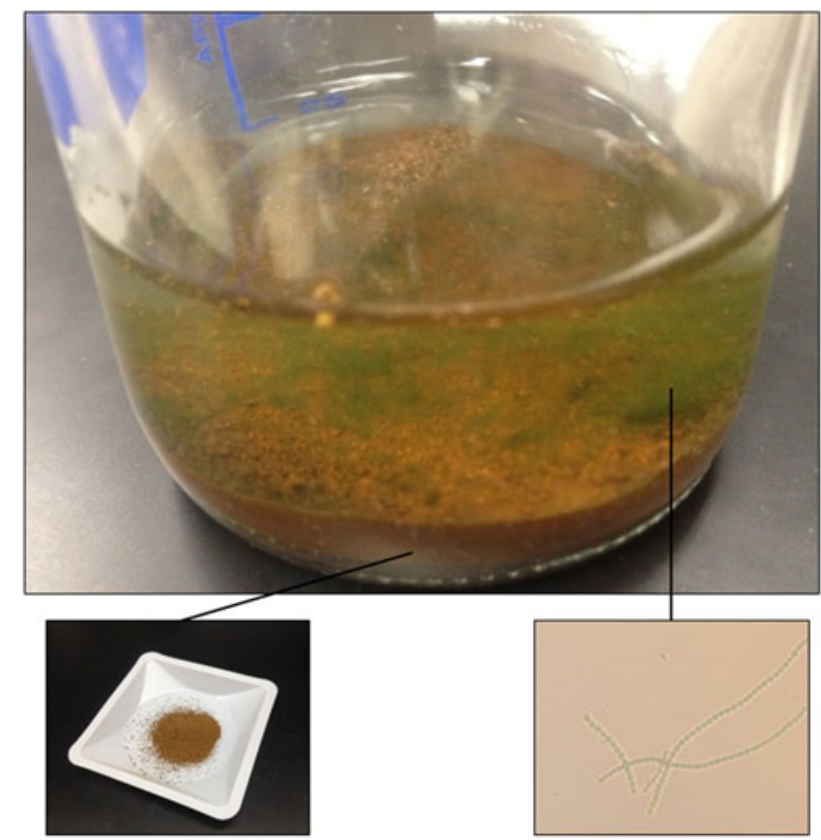

Mars regolith simulant

Anabaena sp. cells

Fig. 4. Anabaena sp. PCC7120 growing in distilled water containing JSC Mars-1A regolith simulant, in Lynn Rothschild's laboratory.

\section{Atmospheric pressure and composition}

Use of the minimal suitable pressure would greatly lower construction weight and cost of cyanobaterial culture systems on Mars, and would minimize the risk of organic matter leakage (Lehto et al. 2006). Relying on a gas composition which is as close as possible to Mars's would make the establishment of such systems even simpler and cost-effective.

What is this minimal suitable pressure? No clear answer has been given to this question, as little work has been focused on microbial growth at low pressure. The lowest pressure at which biological niches are naturally present on Earth is about $330 \mathrm{hPa}$ (at the top of the Mount Everest), way above Mars's surface pressure of about 5-11 hPa (Fajardo-Cavazos et al. 2012). Although viable bacteria have been sampled a few times from stratospheric air above $30 \mathrm{~km}$ (e.g., Wainwright et al. 2003), where atmospheric pressure goes down to Mars's surface pressure, no microbial growth there was indisputably evidenced. Some methanogens can keep metabolic activity (shown by detectable $\mathrm{CH}_{4}$ production) at $50 \mathrm{hPa}$ of pressure under simulated Martian environmental conditions (Kral et al. 2011; Schirmack et al. 2014), and a few bacteria such as Serratia liquefaciens (Schuerger et al. 2013) and isolates from Siberian permafrost samples (Nicholson et al. 2013) have been grown under $7 \mathrm{hPa}$ of $\mathrm{CO}_{2}$-enriched anoxic atmospheres, but a wide range of microorganisms have been shown to be unable to grow on a semisolid agar medium at pressures below 25 hPa of ambient air (Nicholson et al. 2010).

It might be possible to decrease the lowest suitable pressure. As no biological niche is naturally present on Earth at pressures close to Mars's, selective pressure is virtually non-existent for current terrestrial microorganisms and the full potential for 
growth at low pressures is probably far from being reached. There might thus be much room for improvement by artificially evolving cyanobacteria to grow faster under low (and to grow at lower) pressures, including low pressures of Mars-like gas compositions. Consistently, an isolate of B. subtilis showed increased fitness at $50 \mathrm{hPa}$ after a 1000 generation culture at this pressure (Nicholson et al. 2010). The minimal suitable pressure can also be dependent on atmospheric composition, as described below, and on medium type (liquid or solid). It should however be noted that a physical limitation derives from the need to maintain a liquid phase at growth-permissive temperatures.

In recent experiments, a decreased atmospheric pressure (50 kPa instead of the ambient $100 \mathrm{kPa}$ ) negatively affected the growth of cyanobacteria from several genera (Qin et al. 2014). But this was performed under ambient gas composition and, like atmospheric pressure, atmospheric composition matters. $\mathrm{CO}_{2}$ and $\mathrm{N}_{2}$ are present in Mars's atmosphere but their partial pressures differ from Earth's (see Table 1). Mars's higher-than-Earth $\mathrm{pCO}_{2}$ (6.67 versus $\left.0.38 \mathrm{hPa}\right)$ might actually be beneficial: elevated levels of $\mathrm{CO}_{2}$ can have a fertilizing effect on cyanobacterial cultures (Murukesan et al. 2015). Below one atmosphere of pressure, $\mathrm{CO}_{2}$ seems to become the limiting factor and cyanobacteria benefit from much higher-than-normal $\mathrm{CO}_{2}$ concentrations; Synechocystis sp. PCC 6803 was shown to grow more than three times faster under $100 \mathrm{hPa}$ with $5 \% \mathrm{CO}_{2}$ (as well as under 1 bar with $5 \% \mathrm{CO}_{2}$ ) than under 1 bar of ambient air $\left(0.04 \% \mathrm{CO}_{2}\right)$, and to grow under $33 \mathrm{hPa}$ of $100 \% \mathrm{CO}_{2}$ with growth rates close to those obtained under 1 bar of ambient air (Lehto et al. 2007; see the culture system in Fig. 5). Later results showed that an increase in $\mathrm{CO}_{2}$ concentration (at least up to $20 \%$, even though growth rates started to decrease after $10 \%$ for the 1 -bar samples) under either 1 bar or $100 \mathrm{hPa}$ leads to higher growth rates than ambient air composition at the corresponding pressure (Murukesan et al. 2015; unpublished data). Thus, this strain seems to benefit from higher-than-usual $\mathrm{pCO}_{2}$, with a saturation about $4 \mathrm{hPa}$, at which level an around 3.5-fold increase in growth rates is observed for cells previously grown in ambient terrestrial atmosphere. When $\mathrm{CO}_{2}$ is not limiting, its growth rates are not negatively affected by a 10 -fold reduction in atmospheric pressure. Similarly, cultures of $A$. platensis and $A$. cylindrica were shown to benefit from higher-than-ambient $\mathrm{CO}_{2}$ concentrations (Murukesan et al. 2015). Finally, at least some cyanobacteria are able to survive (Synechococcus PCC7942, Anabaena sp.) and even to grow (Plectonema boryanum) in liquid culture under 1 bar (1000 $\mathrm{hPa}$ ) of pure $\mathrm{CO}_{2}$, at least in the short term, when $\mathrm{pCO}_{2}$ is gradually increased by $150 \mathrm{hPa} \mathrm{day}^{-1}$ (Thomas et al. 2005). If needed, bacterial resistance to high $\mathrm{CO}_{2}$ levels could probably be further increased by preventing $\mathrm{pH}$ decrease in the medium, which happens due to carbonic acid $\left(\mathrm{H}_{2} \mathrm{CO}_{3}\right)$ formation when $\mathrm{CO}_{2}$ dissolves in water.

The most striking shortage of substrates on Mars derives from the low partial pressure of $\mathrm{N}_{2}\left(\mathrm{pN}_{2}\right)$ in the atmosphere and the presumed low availability of $\mathrm{N}$ in the regolith. Some work performed with Azotobacter vinelandii and Azomonas agilis showed that microbial $\mathrm{N}$ fixation is possible at a $\mathrm{pN}_{2}$
Table 1. Environmental parameters on Mars and Earth surfaces (adapted from Graham [2004] and Kanervo et al. [2005])

\begin{tabular}{lll}
\hline Parameter & Mars & Earth \\
\hline Surface gravity & $0.38 \mathrm{~g}$ & $1.00 \mathrm{~g}$ \\
Mean surface temperature & $-60^{\circ} \mathrm{C}$ & $+15^{\circ} \mathrm{C}$ \\
Surface temperature range & -145 to $+20^{\circ} \mathrm{C}$ & -90 to $+60^{\circ} \mathrm{C}$ \\
Mean PAR photon flux & $\begin{array}{c}8.6 \times 10^{19} \text { photons } \\
\mathrm{m}^{-2} \mathrm{~s}^{-1}\end{array}$ & $\begin{array}{c}2.0 \times 10^{20} \text { photons } \\
\mathrm{m}^{-2} \mathrm{~s}^{-1}\end{array}$ \\
UV radiation spectral range & $>190 \mathrm{~nm}$ & $>300 \mathrm{~nm}$ \\
Atmospheric pressure & $5-11 \mathrm{hPa}$ & $1013 \mathrm{hPa}$ (mean at \\
\multicolumn{4}{|l}{ Atmospheric composition (average) } & sea level) \\
$\mathrm{N}_{2}$ & $0.189 \mathrm{hPa}, 2.7 \%$ & $780 \mathrm{hPa}, 78 \%$ \\
$\mathrm{O}_{2}$ & $0.009 \mathrm{hPa}, 0.13 \%$ & $210 \mathrm{hPa}, 21 \%$ \\
$\mathrm{CO}_{2}$ & $6.67 \mathrm{hPa}, 95.3 \%$ & $0.38 \mathrm{hPa}, 0.038 \%$ \\
$\mathrm{Ar}$ & $0.112 \mathrm{hPa}, 1.6 \%$ & $10.13 \mathrm{hPa}, 1 \%$ \\
\hline
\end{tabular}

of $5 \mathrm{hPa}$, even though below $400 \mathrm{hPa}$ growth rates decreased with decreasing $\mathrm{pN}_{2}$ (Klingler et al. 1989). The lower limit for $\mathrm{N}$ fixation might vary among species and is still to be defined, but it has been proposed to be within the range of 1-10 hPa (McKay \& Marinova 2001). Crossing this limit using Mars's air composition would require at least 5-50 times the local ambient pressure (reaching a total pressure of approximately $40 \mathrm{hPa}$ to $40 \mathrm{kPa}$ ). However, $\mathrm{pN}_{2}$ would still be limiting and higher values are needed for efficient processes. Rather than only increasing the total pressure to reach adequate $\mathrm{pN}_{2}$ values, $\mathrm{N}_{2}$ could be concentrated by separating $\mathrm{CO}_{2}$ from the other atmospheric gases (mainly $\mathrm{N}_{2}$ and Ar) and mixing them in different proportions to reach an appropriate $\mathrm{pN}_{2}$ value in an otherwise optimized total pressure. Gas separation techniques are well developed (see, for instance, Meyer \& McKay 1996 and Zubrin \& Wagner 2011) and could be based on processes routinely used by industry on Earth. Assuming similar $\mathrm{pN}_{2}$ needs for cyanobacteria as for A. vinelandii and $A$. agilis (see Klingler et al. 1989), a $\mathrm{pN}_{2}$ of $95 \mathrm{hPa}$ would only slightly limit growth (experiments are planned to define the lowest $\mathrm{pN}_{2}$ allowing efficient growth of diazotrophic cyanobacteria). For wild-type, diazotrophic cyanobacteria, a $100 \mathrm{hPa}$ atmosphere with $95 \% \mathrm{~N}_{2}$ and nonlimiting $(5 \%) \mathrm{CO}_{2}$ could thus lead to higher growth rates than an Earth-like atmosphere. Cultures could also be supplemented with $\mathrm{N}$ recycled from human and biomass waste, even though this should not be the only $\mathrm{N}$ source as sustainability and expandability would be compromised.

Depending on its adjusted pressure, a Martian-like atmosphere can strongly affect other aspects of the lithotrophic growth of cyanobacteria through indirect effects (e.g., a lowered $\mathrm{pH}$ due to $\mathrm{H}_{2} \mathrm{CO}_{3}$ formation can influence both cell viability and nutrient release from substrates). As for all processes suggested here, extensive and faithful simulations of culture conditions expected to be provided on-site are needed.

Atmosphere of selected gas composition and pressure could be provided within inflatable, tunnel-like containments (Lehto et al. 2006). Tight sealing should allow the desired pressure to be maintained, and adjusted gas supply systems could allow $\mathrm{CO}_{2}$ and some $\mathrm{N}_{2}$ to be provided from Martian 


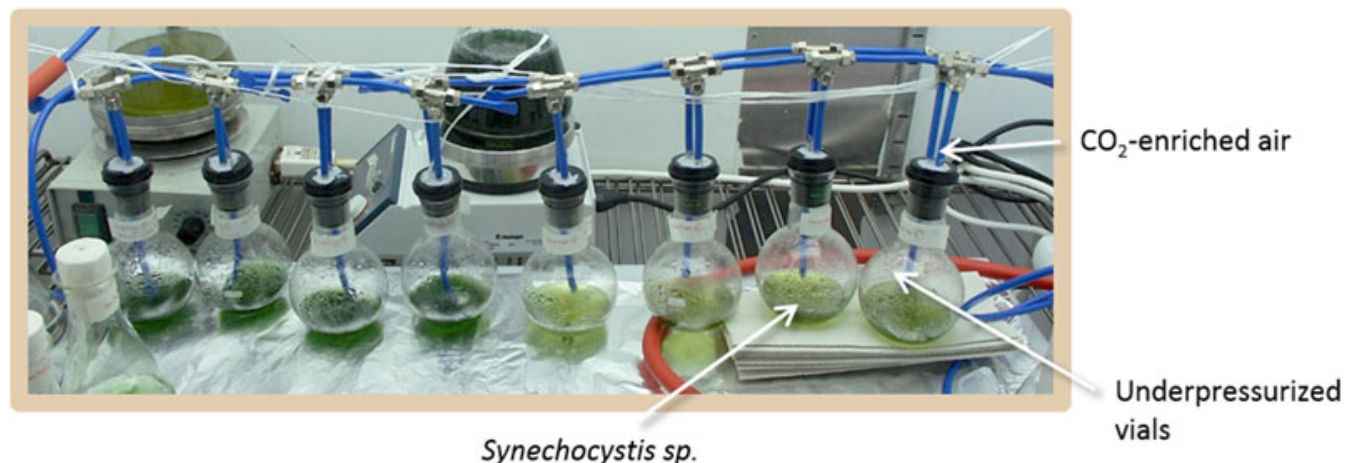

Fig. 5. Underpressurized culture vials used in Kirsi Lehto's laboratory (at the University of Turku, Finland) to grow cyanobacteria in low-pressure/high $\mathrm{pCO}_{2}$ atmospheres.

atmosphere - possibly after $\mathrm{N}$ enrichment. An onion-like structure, with a pressure gradient throughout layers, has also been proposed. This would offer the additional advantages of a better filtering of the Martian dust and a better thermal insulation (Lehto et al. 2006).

\section{Water}

One of the most critical resources to provide to cyanobacterial cultures will be water. As water is needed within human outposts, regardless of the use of cyanobacteria, various hardware systems for its extraction and processing on Mars have been suggested elsewhere. There follow a few examples of water sources and mining techniques under consideration. This list is not exhaustive.

Water could be generated on Mars by importing $\mathrm{H}_{2}$ from Earth and combining it to $\mathrm{O}$ from local $\mathrm{CO}_{2}$ (Zubrin et al. 1991) but, even though $\mathrm{H}$ represents only $11 \%$ by weight of pure $\mathrm{H}_{2} \mathrm{O}$, relying on imported $\mathrm{H}_{2}$ would strongly limit the autonomy and sustainability of human outposts. However, water can be found in various forms throughout Mars (reviewed in Tokano 2005; Rapp 2007 and Cockell 2014). It is present in large amounts as ice at the north polar ice cap and under the south carbon ice cap, and throughout the planet as nearsurface deposits of water ice. The presence of liquid water has to date not been unquestionably established, but several lines of evidence strongly suggest transient liquid brines (Zisk \& Mouginis-Mark 1980; McEwen et al. 2011; Martín-Torres et al. 2015). It might also exist below the cryosphere, in areas where temperatures and pressures are high enough (e.g., Clifford et al. 2010), possibly within drilling range. The abundance, location and nature of near-surface water deposits is still to be accurately determined, but mining these to generate usable water may be practical (e.g., Rapp 2013). If it appears that mining liquid water or large ice deposits cannot be done, water could be extracted from the soil's hydrated minerals. Energy requirements for heating soil at $500^{\circ} \mathrm{C}$ in an oven, before collecting steam, have been assessed to be about $5.2 \mathrm{kWh} \mathrm{kg}^{-1}$ of water in a $2 \%$-water soil, plus a small amount (below $0.1 \mathrm{kWh} \mathrm{kg}^{-1}$ of water) for excavating and conveying the soil (Stoker et al. 1993). Other processes where soil is heated for water extraction are under consideration, including the use of focused light and of microwaves, the latter being one of the most promising regarding energy requirements, mass and reliability (Wiens et al. 2001; Ethridge \& Kaulker 2012). A team of the Colorado School of Mines designed a system, referred to as the Microwave Pizza Oven, aimed at extracting water from the soil of Mars using microwaves (generated using about $12 \mathrm{kWh} \mathrm{kg}^{-1}$ of water, provided by silicon solar cells) in conjunction with a conveyor belt mechanism to process soil and extract bound water. Expected yields are in the order of $1 \mathrm{~kg}$ of water per $2.5 \mathrm{~h}$ in a $2 \%$-water soil, for a system's mass below $20 \mathrm{~kg}$ (Wiens et al. 2001). The use of microwave heating could also reduce dramatically excavation needs, as microwaves could be inserted down bore holes to heat at desired depths (Ethridge \& Kaulker 2012). But energy and excavation needs for water extraction from the soil could be further reduced: according to Zubrin \& Wagner (2011), a $0.1 \mathrm{~mm}$ thick polyethylene dome could be used to farmselected soil sites by increasing temperature and collecting volatilized water in a cold trap device. Using this approach, a $25 \mathrm{~m}, 100 \mathrm{~kg}$ dome ringed by reflectors could allow about $150 \mathrm{~kg}$ of water to be farmed in an $8 \mathrm{~h}$ day from a soil with $2 \%$ water (Zubrin \& Wagner 2011).

There is also water vapour in the atmosphere. Relying on it rather than on soil water would remove the need for processing regolith and/or to move to new locations once a site has been dried up. Concentrations vary through time and location and are very low, but total atmospheric water has been assessed to amount to approximately $1.3 \mathrm{~km}^{3}\left(1.3 \times 10^{9}\right.$ litres $)$, in very large excess compared with human need for a research base, and extracted water would be renewed naturally by exchange with regolith and polar caps (McKay et al. 1993). In spite of the large volumes of atmosphere that need to be processed, water extraction from the Martian atmosphere could be done with an energy consumption below $100 \mathrm{kWh} \mathrm{kg}^{-1}$ using a process of atmosphere cooling/compression and water condensation designed by Meyer \& McKay (1984) and improved by Clapp (1985). Note that energy used in this process would not be dedicated to water extraction, as atmospheric gas could be isolated using the same setup. Energy needs for water extraction from the atmosphere could be brought further down, as shown by a system referred to as the Water Vapour 
Adsorption Reactor (WAVAR). In WAVAR, atmosphere is filtered and drawn through a regenerative adsorbent bed of zeolite molecular sieve, from which water is later desorbed using microwave radiation (Williams et al. 1995; Coons et al. 1997; Schneider \& Bruckner 2003). Energy consumption has been assessed as ranging from approximately 3 to 30 $\mathrm{kWh} \mathrm{kg}^{-1}$ of water, depending on time and location (Grover \& Bruckner 1998). Additional water could be recycled from human metabolism (about $0.4 \mathrm{~kg}$ of transpiration water and respiration moisture a day per crewmember) and human waste (Meyer \& McKay 1989; Tikhomirov et al. 2007). It will also be a by-product of physicochemical processes such as on-site production of biofuels and materials (e.g., Zubrin et al. 1997). The systems described above are still in their infancy; increasing knowledge of Mars's resources, coupled to engineering effort, will likely support the development of more efficient water mining technologies and processes.

Strategies can also be developed to minimize water needs for cyanobacterial culture systems, in addition to recycling water from culture effluents. For the production of some products where cells lysis is not needed, water requirements (as well as requirements for maintenance, nutrients and energy) could be reduced by immobilizing cyanobacteria within polymeric matrices. Such entrapment can preserve cyanobacteria's metabolic activities for prolonged periods of time, up to several years (Lukavský 1988; Hertzberg \& Jensen 1989; Chen 2001). Water requirements could be further reduced by growing terrestrial cyanobacteria as biofilms, directly on the surface of Martian rocks, in a semi-closed environment where suitable temperature, pressure and moisture are provided. Such a growth system could be relatively close to the natural lifestyle of rock-dwelling cyanobacteria, noteworthy in terrestrial deserts (see, e.g., Friedmann \& Ocampo 1976; de la Torre et al. 2003; Warren-Rhodes et al. 2006 and Billi et al. 2013) but with more favourable moisture, UV protection and temperatures.

Finally, a reduced pressure at growth-permissive temperatures, as envisioned in the culture system, will foster water evaporation. However, if $\mathrm{pN} 2$ sets the lower limit for atmospheric pressure and the culture system provides about a tenth of Earth's atmospheric pressure at sea level (see subsection 'Atmospheric pressure and composition'), evaporation can easily be reduced by saturating the incoming air with water vapour (Kirsi Lehto, personal communication). Besides, as the system needs to be air-tight (apart from controlled gas exchange), water loss by evaporation can be minimized.

\section{Solar energy and harmful radiations}

On Earth, the solar flux is in large excess compared with the needs of cyanobacteria and green plants, which cannot use more than about $10-20 \%$ of maximal sunlight on the surface (Way et al. 2011). Some cyanobacterium species such as Arthrospira spp. can utilize higher light densities but, at least for $A$. platensis, the radiation level for maximal photosynthesis activity is well below terrestrial mean day values - provided agitation intensity and cell density allow sufficient exposure (Hoshino et al. 1991). Even though Mars is on average 1.52 times farther from the Sun than Earth and consequently receives about $43 \%$ as much sunlight at comparable latitude and time of day, this is in excess compared with photosynthesis needs, even in the case of a dust storm (McKay et al. 1993). The light flux needed for optimal photosynthesis of many cyanobacterial species is about $3 \times 10^{19}$ photons $\mathrm{m}^{-2} \mathrm{~s}^{-1}$, which is only about $10 \%$ of Mars's average ambient light flux (Lehto et al. 2007). At lower light levels photosynthesis is still possible, albeit at lower efficiencies. It has for example been assessed that, at midday at vernal equinox, light levels on Mars are about 5000 times greater than the minimum required for photosynthesis (Cockell \& Raven 2004).

It might be thought challenging to let photosynthetically active radiation (PAR light; 400-700 $\mathrm{nm}$ ) reach cultures while protecting the latter from harsh radiation - namely UV radiation, solar energetic particles (SEP) and galactic cosmic rays (GCR). First, the fraction of biologically effective UV radiation reaching the surface of Mars is much greater than that reaching the surface of Earth and includes UV-C radiation $(<280 \mathrm{~nm})$. The models of Cockell et al. (2000) and Schuerger et al. (2003) predict a maximum flux of around $50 \mathrm{~W} \mathrm{~m}^{-2}$ of $\mathrm{UV}_{200-400 \mathrm{~nm}}$ irradiance on the equatorial Martian surface at the mean orbital distance. Recent data from the Curiosity rover suggest lower values, with a maximum $\mathrm{UV}_{200-380 \mathrm{~nm}}$ irradiance of about $20 \mathrm{~W} \mathrm{~m}^{-2}$ recorded at midday at Gale's crater (Gómez-Elvira et al. 2014). Despite being strongly germicidal on the surface, this radiation can be blocked by a few millimetres of Martian dust coverage (Mancinelli \& Klovstad 2000; Dartnell \& Patel 2014) or, to let PAR light in, by mere transparent covers such as glass filters.

Besides UV, ionising radiations of SEP and GCR can reach the Martian surface and subsurface with high energies due to Mars's lack of intrinsic magnetic field and thin atmosphere. Pavlov et al. (2012) and Dartnell et al. (2007) assessed absorbed dose rates at the surface to be in the range of $50-150 \mathrm{mGy} \mathrm{yr}^{-1}$, and data from the Curiosity rover indicate an absorbed dose rate of $76 \mathrm{mGy} \mathrm{yr}^{-1}$ at Gale crater (Hassler et al. 2013). Could cells be protected from this radiation? Even though the primary cosmic radiation component decreases with shielding, secondary particles (lighter particles including neutrons and gamma-rays) form when radiation penetrates substrates and dose rates increase with shielding until the Pfotzer maximum, before decreasing due to energy loss, absorption and decay processes. From $76 \mathrm{mGy} \mathrm{yr}^{-1}$ at the surface, for instance, they reach $96 \mathrm{mGy} \mathrm{yr}^{-1}$ under $10 \mathrm{~cm}$ of Martian rock with a density of $2.8 \mathrm{~g} \mathrm{~cm}^{-3}$ (Hassler et al. 2013). The design of culture chambers and the choice of material used for shielding should take into account their interactions with primary radiations on the Martian surface (see Le Postollec et al. 2009).

Approximately $5 \mathrm{~m}$ of Mars dirt would confer a protection to radiation equivalent to Earth's atmosphere (McKay et al. 1993). However, bacterial cells are overall much more radiation-resistant than human cells and such a protection is unlikely to be needed. In addition, cyanobacteria are known to have high ploidy levels (Griese et al. 2011), pigments and specific morphological features which tend to increase radio- 
resistance. The resistance of cyanobacteria to photon irradiation (gamma-rays and X-rays) has been studied as early as in 1951 (Bonham \& Palumbo 1951), and the high resistance of some species was observed in the early 1960s (Shields et al. 1961; Godward 1962). In the following decade, the resistance of a wide range of species from various genera was tested. Resistance appeared to be highly variable among species, ranging from sensitive ones with $\mathrm{D}_{10}$ (dose required to reduce the viable number of cells by $90 \%$ ) below $1 \mathrm{kGy}$ to highly resistant ones with $\mathrm{D}_{10}$ above $10 \mathrm{kGy}$ (e.g., Shields et al. 1961; Godward 1962; Bruce 1964; Kumar 1964; Kraus 1969; Asato 1971). These results were confirmed and deepened by recent studies. Synechococcus and Synechocystis spp. were shown to be relatively sensitive to gamma rays, with $\mathrm{D}_{10}$ of about $0.3 \mathrm{kGy}$ (Domain et al. 2004; Agarwal et al. 2008) and $0.7 \mathrm{kGy}$ (Domain et al. 2004), respectively. Two Anabaena strains were shown to tolerate a $5 \mathrm{kGy}$ gamma-ray dose without loss of survival, to have a $\mathrm{GI}_{50}$ (dose where growth is inhibited by $50 \%$ ) of 6-11 kGy and to survive doses of $15 \mathrm{kGy}$ (Singh et al. 2010; Singh et al. 2013). Arthrospira sp. PCC 8005 cells were shown to be able to survive exposure to doses of at least $6.4 \mathrm{kGy}$ of gamma irradiation, $1 \mathrm{kGy}$ of He particle radiation and $2 \mathrm{kGy}$ of $\mathrm{Fe}$ particle radiation (Badri et al. 2015). Chroococcidiopsis spp. cells were shown to withstand $2.5 \mathrm{kGy}$ of X-ray irradiation in liquid culture with small to medium viability loss: $20-65 \%$, depending on the strain, with a $D_{10}$ of 2-5 kGy (Billi et al. 2000a). Viable Chroococcidiopsis spp. cells were also recovered after exposure to $15 \mathrm{kGy}$ of $\mathrm{X}$-rays (Billi et al. 2000a) and to $12 \mathrm{kGy}$ of gamma-rays (Verseux et al. manuscript in preparation). Moreover, no significant DNA or membrane damage was detected after exposure to $1 \mathrm{kGy}$ of He particle radiation, $2 \mathrm{kGy}$ of Fe particle radiation or 1 kGy of Si particle radiation (Verseux et al. manuscript in preparation). A dose of $1 \mathrm{kGy}$ roughly corresponds to a thousand years on the Martian surface, a timeframe way beyond that of division and repair of metabolically active cyanobacteria; cells are therefore not expected to be affected in BLSS cultures. The biological effect of ionizing radiation cannot be assessed based on the dose only: other parameters are to be taken into account - for instance, the composition of the radiation flux and its modification when interacting with the environment and the cells' properties - but the studies mentioned above show the orders of magnitude involved. Even if the effect of radiation on Mars was, at equivalent dose, more damaging by several orders of magnitude than the radiation flux used in these studies, the replication time and repair dynamics of even slowgrowing strains would be way below the time needed to receive a sterilizing dose. Consistently, it has been estimated that even vegetative cells of the bacterium $E$. coli could survive the ionizing radiation dose that would be received after more than a thousand years on the surface of Mars (Dartnell et al. 2007). More generally, ionizing radiation on Mars is not expected to prevent microbial life (Dartnell et al. 2007; Horneck 2008).

Cultures could be buried inside regolith or covered with regolith-based material: although not expected to be needed for radiation protection, regolith shielding could be relevant for temperature control (taking advantage of the regolith's thermal insulating properties) and protection from the wind and dust. Manufacturing processes could be simple and costeffective, taking for instance advantage of: (i) the cement-like properties of unprocessed regolith mixed with water (McKay \& Allen 1996); (ii) the ubiquity of clay-like materials on Mars; (iii) the large fraction (about $40 \%$ by weight of Viking 1 and 2 soil samples) of Martian soil represented by silicon dioxide (the basic constituent of glass); and (iv) the fact that plastics may be derived from local $\mathrm{C}$ and $\mathrm{H}$ (Zubrin \& Wagner 2011). In this case, artificial lighting, mirrors or fibre optics could be used to bring PAR light to the cultures. Lighting could also be electrically powered, using for instance solar, wind or geothermal energy sources. Various studies have been performed regarding electrical lighting for plants in BLSS (easily adaptable to cyanobacterial culture), light-emitting diode (LED)-based systems being the most promising (Massa et al. 2007). However, even though electrical lighting would allow an accurate control on light intensity and photoperiods, energy and mass requirements could be greatly reduced - compared with electrical lighting - by using systems based on fibre-optics technology to harvest and transmit selected wavelengths from solar energy. Several of such systems have been developed in the context of space exploration, among others for the cultivation of microbial phototrophs (Mori et al. 1987) and plants (Jack et al. 2002; Nakamura et al. 2009). Equivalent system mass calculations showed a net benefit of using solar lighting rather than electric lighting in this context, under realistic mission assumptions (Drysdale et al. 2008). The cost effectiveness of such systems may be limited by temporary decreases in light availability (due to diurnal and seasonal light cycles, variable distance from the Sun and global dust storms), which drives a need for increasing collector size relative to culture areas, and may consequently be inadequate for growing plants in Mars BLSS (Massa et al. 2007). They could however represent a solution for growing cyanobacteria, which use light more efficiently and suffer less than plants from temporary reduction of light and from changes in illumination patterns. That being said, the simplest and most cost-effective way of providing PAR could be to directly expose cultures to solar light while protecting them from lethal levels of radiation. A transparent but UV-blocking and thermal insulating material, which should also be resistant to Mars surface conditions in the long term, could be used. Radiation coming from straight above could also be stopped by regolith-based materials, while allowing light to come from the sides at adequate intensities for photosynthesis to occur (de Vera et al. 2014).

Heating will be needed to maintain liquid water and allow metabolism. Heating systems could be either directly based on solar energy, or on electricity generated by solar energy (e.g., using solar panels) and/or based on other power sources used within Martian outposts (e.g., wind, geothermal activity or fuels produced on site). This issue is largely documented elsewhere, as it applies to other components of human colonies such as habitats, and will not be detailed here. 


\section{Gravity}

Would Mars's lower-than-Earth gravity affect cyanobacteria? The earliest microbiology experiments in space, reported in the early 1960s, did not show any effect of microgravity on individual cells (Zhukov-Verezhnikov et al. 1962). Consistently, theoretical studies suggested that microgravity would not directly affect cells of a diameter below $10 \mu \mathrm{m}$, in part due to the density uniformity and smallness of intracellular components (Pollard 1965, 1967). Later, experiments on-board the orbital station Salyut 6 and biosatellites Kosmos 1887 and 2044 showed that unicellular algae were not affected in their development by microgravity (Sychev et al. 2001). However, a wide range of altered behaviour and growth properties such as increased virulence, reduced lag phase, increased final cell population, increased productivity of secondary metabolites and increased conjugation rates have been reported in later microbiology experiments in spaceflight and simulated microgravity (see, e.g., Nickerson et al. 2000; Benoit \& Klaus 2007 and Wilson et al. 2007), in various prokaryotes including cyanobacteria (Wang et al. 2004, 2006; Xiao et al. 2010). A well-supported hypothesis suggests that these effects are motility-dependent, with non-motile cells being the most affected. This might be explained by the reduced flow of metabolites and nutrients and by the reduced exchanges between bacteria and the environment (e.g., because mass-driven convection does not occur), which result in a modified chemical environment around cells that alters biological responses (Horneck et al. 2010). However, microgravity was shown not to reduce $\mathrm{N}$ fixation abilities, photosynthetic $\mathrm{O}_{2}$ production rates or growth in cyanobacteria (e.g., Wang et al. 2006). Mars's reduced gravity $(0.38 \mathrm{~g})$ is consequently not expected to be an obstacle to cyanobacterium-based processes, especially if stirring generates a non-limiting flux of nutrients and metabolites. Studies aimed at confirming that reduced gravity do not alter cell processes of interest would however be useful.

\section{Engineering cyanobacteria}

In addition to adapting the Martian environment to cyanobacteria, work can be done to adapt cyanobacteria to the Martian environment. Synthetic biology may provide the tools for this. This field, or set of fields, aroused NASA's interest due to its potential for engineering microorganisms with useful features for resource production in space (Cumbers \& Rothschild 2010; Langhoff et al. 2011; Menezes et al. 2014; Verseux et al. 2016). In the present context, the use of synthetic biology tools and methods is investigated for optimizing the abilities of selected cyanobacteria to: (i) withstand environmental stresses faced during space exploration missions, and (ii) grow and perform biological functions of interest under on-site constraints (see Fig. 6).

Increasing cyanobacteria's abilities to withstand extreme conditions would allow failure risk and culture system-related costs to be minimized (Cockell 2010; Olsson-Francis \& Cockell 2010). First, for storage during the journey: cells' tolerance to long periods of dehydration, possibly in a differentiated state (e.g., akinetes), would allow a storage free of risk of loss by freezing failure. Secondly, for growth on site: higher tolerance to Mars's environmental factors would reduce the required level of shielding. It would also increase safety in case of system malfunction during which cultures could be exposed to harsher conditions (e.g., desiccation, low pressure, high radiation levels, altered $\mathrm{pH}$ and sudden temperature shift), either when stored or grown. Thirdly, increasing the abilities of cyanobacteria to rely on on-site resources would allow productivity to be increased while relaxing constraints and supplementation needs. In particular, it would be highly beneficial to increase their abilities to leach Martian mineral resources and to get most of their nutrients from these, within a wide range of $\mathrm{pH}$, and to fix $\mathrm{N}$ at a lower $\mathrm{pN}_{2}$. Finally, new functions and nutritional properties could be engineered and optimized under conditions that would be provided within Mars bases.

To increase their resistance, cyanobacteria could be transformed with heterologous genes known to increase fitness under conditions found on the surface of Mars (Cumbers \& Rothschild 2010). This approach has been successful in other contexts: for instance, E. coli's resistance to gamma irradiation, to desiccation and to low temperatures has been increased by expressing, respectively, the PprI protein from Deinococcus radiodurans (Gao et al. 2003), a sucrose-6phosphate synthase from Synechocystis sp. strain PCC 6803 (Billi et al. 2000b) and the chaperonin Cpn60 and cochaperonin Cpn10 from the psychrophilic bacterium Oleispira antarctica (Ferrer et al. 2003). Once specific genes have been shown to confer an advantage to a targeted stress in a target organism, they could be improved using various computational and molecular biology tools and methods. These are becoming more and more efficient thanks to, among other factors, a sharp decrease in DNA synthesis costs, the improvement of automated gene assembly methods, and the development of biological computer-aided design (BioCAD) and other computational tools.

However, despite the fact that expressing heterologous genes (or overexpressing homologous genes) may confer a significant advantage in coping with some environmental stressors, this approach might be much more challenging for resistance features which are highly multifactorial, each individual factor having a relatively weak impact. There is not a single factor that confers on $D$. radiodurans its extreme radiation resistance, for instance, but a very wide combination of features, including efficient DNA repair mechanisms, anti-oxidation mechanisms and specific morphological features (see, for instance, Slade \& Radman 2011). For this kind of feature, dramatic increases through rational design seem very challenging given bio-engineering's current state-of-the-art. Instead, directed evolution - iterations of mutagenesis and artificial selection at the scale of the whole organism can allow complex modifications, affecting both known and unknown mechanisms. The dynamics of experimental evolution have been widely studied in recent decades and have been successfully used to increase organisms' specific properties (see, e.g., Elena \& Lenski 2003 and Conrad 2011), including radiation resistance in bacteria 


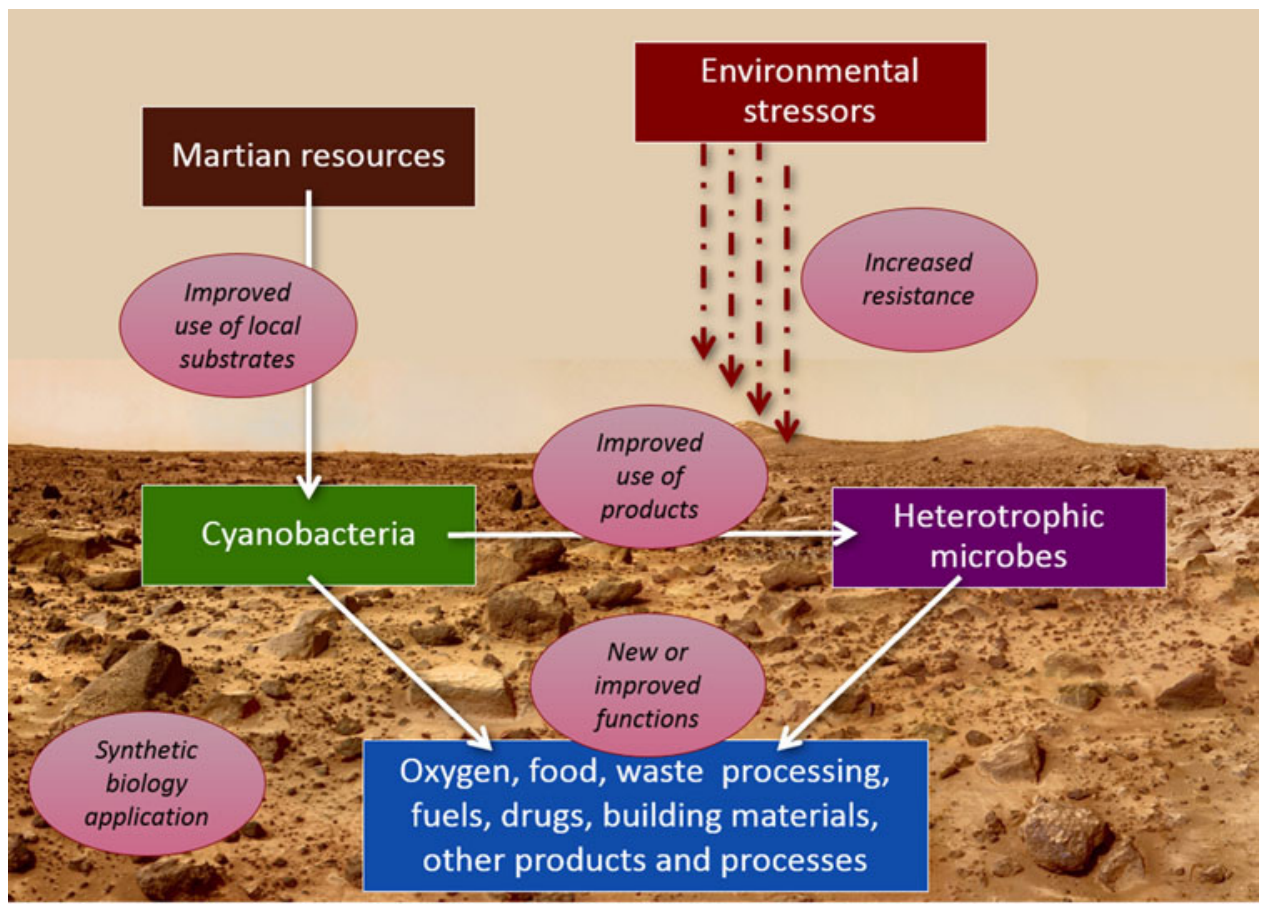

Fig. 6. Simplified overview of the potential roles of synthetic biology in the development of Mars-specific, cyanobacterium-based BLSS.

(Ewing 1995; Harris et al. 2009; Wassmann et al. 2010; Goldman \& Travisano 2011).

For increasing the abilities of cyanobacteria to use resources found on-site, and for conferring on them abilities (and/or improving these abilities) to produce resources of interest from local resources, rational genetic engineering might be more efficient than it is for increasing resistance. Some clues have even been given regarding the engineering of microorganisms with increased bioleaching abilities (Cockell 2011). However, despite metabolomics's great advances in the last decade and the synthetic biology benefiting from it (see, for instance, Ellis \& Goodacre 2012 and Lee 2012), the complex interactions occurring in cells are still hard to predict and whole-cell-scaled directed evolution will here again be very useful.

One of the main issues when designing an optimization process based on directed evolution is the need for either linking the optimized function (e.g., production of a compound of industrial interest) to organisms' fitness or selecting mutants after screening. When increasing resistance to environmental stressors (e.g., low pressure or radiation) or abilities to use a given nutrient source (e.g., Martian regolith or atmosphere), the process is more straightforward: selection can be done by applying increasing levels of the targeted stress (when improving resistance) or by conducting growth/re-inoculation cycles to let fast-growing mutants become dominant (when improving use of a given nutrient source). Directed evolution can be improved by automation (Dykhuizen 1993; de Crecy et al. 2009; Marlière et al. 2011; Grace et al. 2013; Toprak et al. 2013) and by recent methods such as, for instance, genome shuffling (Patnaik et al. 2002) and multiplex genome engineering (Wang et al. 2009). It might also be more efficiently performed on Mars, once a microbial production system is well established and automated (Way et al. 2011): Earth-based simulations of some of the factors encountered on Mars (and their combinations) are difficult, expensive and cannot faithfully reproduce all of their effects. The most straightforward use of directed evolution would be to improve cyanobacterial cultures' productivity by, for example: (i) increasing the abilities of cyanobacteria to grow faster under low (and to grow at lower) pressures, including low pressures of Mars-like gas compositions; (ii) improving their efficiency to extract mineral nutrients from Martian regolith; and (iii) increasing their resistance to potentially toxic elements in the regolith (e.g., perchlorates). As selective pressure for some of these factors is low or inexistent on Earth, fitness under these conditions is likely far from its evolutionary potential and could be largely increased by directed evolution. The amounts of resources allocated to cyanobacterial cultures for producing a given amount of other resources could thereby be significantly reduced. Besides direct applications, performing directed evolution could give clues on whether and how much organisms can genetically adapt to the Martian environment, and therefore help assessing the risk of biological contamination in case of accidental release.

Rational genetic engineering and directed evolution are not mutually exclusive: they can be used in combination (Rothschild 2010). Rationally engineered organisms can be submitted to directed evolution for optimization and, conversely, data obtained from genome sequencing of evolved organisms (so as to understand which mutations are responsible for improved properties) can give gene targets for rational design.

Besides increased resistance and abilities to thrive on local substrates, synthetic biology could be used to confer on 
cyanobacteria specific functions for Mars-specific BLSS. Numerous genetic engineering tools and methods have been developed for enhancing their metabolic capabilities. Various applications which are considered on Earth (see, e.g., Wang et al. 2012 and Berla et al. 2013) could be useful on Mars as well, but others might be developed specifically for this planet (Verseux et al. 2016). Some resources may be much easier to obtain using synthetic biology when on Mars, while being easier to obtain by other means (e.g., by chemical methods, using the natural host or by simply harvesting rather than producing them) when on Earth. Finally, metabolic pathways might differ: the set of potential starting compounds will be much reduced on Mars and some substrates that are cheap and abundant on Earth will be extremely hard to provide there, changing the cost-effectiveness of a given pathway.

A critical issue to be faced is genetic instability: artificial gene constructs might be lost. Plasmids are useful for screening and optimization steps, but are generally too unstable to be used on a large scale and in the long term. Exogenous genes should rather be irreversibly inserted in cyanobacteria's genomes, which leads to much higher stability and more control over expression levels (e.g., Herrero et al. 1990; Heap et al. 2012). Genome insertion in cyanobacteria is made harder than in most model bacteria by their polyploidy and the unviability of recA mutants (Murphy et al. 1990; Matsuoka et al. 2001), but specific methods are available to do so (e.g., Andersson et al. 2000: Takahama et al. 2004; Clerico et al. 2007; Chaurasia et al. 2008). For standard, organism-scaled directed evolution, genome integration will not be an issue as variability will mostly affect genomes. However, even when integrated into a genome, modifications may be lost. How commonly this phenomenon is encountered among teams performing cyanobacterium genetic engineering, and how limiting the issue is, is hard to assess due to a tendency not to document failures (Jones 2014). Many reports of successful and stable genetic constructs in cyanobacteria can be found (e.g., Guerrero et al. 2012; Bentley et al. 2014; Dienst et al. 2014), but a few others document instability (e.g., Takahama et al. 2003; Angermayr et al. 2012). In spite of the lack of available data, it is expected that modifications having a negative effect on growth (e.g., insertion of a system to produce a chemical of no use to the producing cyanobacteria) is more likely to be counter-selected than modifications conferring an advantage on cyanobacteria (e.g., a better ability to use provided substrates or to withstand environmental stress factors) under a given selection pressure, as far as this pressure is maintained. Studies are needed to determine how problematic genetic instability in cyanobacteria is and to develop appropriate solutions

\section{Future research needs}

What would be the efficiency of a cyanobacterium-based BLSS? This question can currently be answered only tentatively. There follows an example of a scenario, with some back-of-the-envelope calculations. Using a strain of wild-type Anabaena sp. and assuming that regolith on Mars is as suitable as a substrate as terrestrial basaltic analogues, obtaining a saturated culture from a tenfold dilution takes, roughly, 1 month (Olsson-Francis \& Cockell 2010; Olsson-Francis et al. 2012; Verseux et al., unpublished data), without taking into account the growth-enhancing effects of a low-pressure/high- $\mathrm{CO}_{2}$ atmosphere and of potential nutrients from recycled human waste products. Starting with a 1 litre culture (or from cyanobacteria concentrated from 1 litre, to further reduce volume and mass) and if the limiting factor was cyanobacterial growth, a $10^{3} \mathrm{~m}^{3}\left(10^{6}\right.$ litre) saturated culture could be obtained within 6 months, and a $1 \mathrm{~km}^{3}\left(10^{12}\right.$ litre $)$ culture within 1 year. Assuming growth rates and final biomass yields as in Olsson-Francis \& Cockell (2010)'s experiments with a basaltic regolith simulant, growth rates would be roughly 0.3 day $^{-1}$ and biomass at saturation $100 \mathrm{mg}^{-1}$. With a $10^{3} \mathrm{~m}^{3}$ culture, $1.5 \times 10^{5}$ litres of culture (corresponding to $15 \mathrm{~kg}$ of dry biomass) could be harvested every day. How do these figures relate to needs in BLSS? Assuming energy contents similar to A. platensis's (Tokusoglu \& Unal 2003), about 500 g of dry biomass per crewmember would cover the crew's caloric needs (as mentioned above, covering caloric needs do not imply providing a healthy diet). If cells produce $\mathrm{O}_{2}$ with yields per unit of dry biomass as C. vulgaris in BIOS-I (Kirensky et al. 1968; Gitelson 1992), the amount of culture used as food would also provide enough $\mathrm{O}_{2}$ for crewmembers' respiration. Based on preliminary results, a 10 litre batch of lysed cyanobacteria could yield $10 \mathrm{ml}$ of a culture medium for heterotrophic microorganisms in which $E$. coli could reach more than $10^{9}$ cells $\mathrm{ml}^{-1}$ in $24 \mathrm{~h}$; the amounts of cyanobacterial culture allocated to the growth of heterotrophic microorganisms would thus be negligible for most applications. Assessing the conversion efficiency of cyanobacterium-to-plant biomass would be too tentative without further experiment; however, given that more than $90 \%$ of plants' dry weight comes from C, O and $\mathrm{H}$ (see, for instance, Latshaw \& Miller 1934), which can be obtained by plant photosynthesis from $\mathrm{CO}_{2}$ and $\mathrm{H}_{2} \mathrm{O}$, it is reasonable to assume that the plant mass-to-cyanobacterium mass ratio can be much higher than 1 , as with nutrients provided in commercial hydroponic systems.

These estimations are far from accurate; firstly, because productivity will be highly dependent on choices which are still to be made and, secondly, because too much biological data are missing. In addition, these estimations are on the pessimistic side, as they are based on preliminary experiments performed in conditions which were not optimized. In this scenario, the time to develop large cultures is not an issue (crewmembers could rely on resources imported from Earth during the first months) but outputs per resource unit can be, and should be, extensively improved. Consequently, much work is still to be done before functional cyanobacteriumbased BLSS are developed. Some of the needed tasks, mostly dealing with optimization and characterization, are briefly described below. This list is not exhaustive and the mentioned requirements have room for flexibility.

Firstly, the most promising strains should be selected according to their relevance for Mars BLSS. Selection criteria can include their abilities to grow under conditions easily 
providable within Mars bases (mainly, to leach Martian regolith analogues, to efficiently fix $\mathrm{N}$, and to be undemanding and flexible regarding nutrient inputs), their resistance to environmental conditions to be faced on Mars and during the journey, their growth rates, their suitability for genetic engineering, their abilities to perform specific tasks and/or their nutritional properties. The best option may be a combination of species rather than a single species, but versatility could reduce the number of strains and keep the system simple. Among interesting candidates are species from the genera $\mathrm{Ar}$ throspira, Cyanothece, Chroococcidiopsis, AnabaenalNostoc and Synechococcus/Synechocystis. As described above, Arthrospira species are well studied in the context of life support because of the high productivity of their cultures, their edibility and their nutritional values. However, these species are demanding in terms of culture conditions, do not seem to efficiently leach regolith (Olsson-Francis \& Cockell 2010) and do not fix N. Cyanothece sp. ATCC 51142 has been proposed as a complement to plants in BLSS due to its relatively high growth rates, $\mathrm{N}$ fixation abilities, versatile metabolism and probable edibility (Schneegurt et al. 1995, 1996; Schneegurt \& Sherman 1996). Chroococcidiopsis species (see Fig. 7) have also been suggested as BLSS components (Billi et al. 2013), as they are dominant in terrestrial sites considered as Mars analogues due to radiation, rock composition, drought and extreme temperatures, and have been shown to be highly resistant to various simulated space and Martian conditions (Thomas et al. 2006; Cockell et al. 2011; Baqué et al. 2013, 2014). Another advantage comes from their resistance to longterm desiccation (Billi 2009), which is of strong interest for long-term storage: cells could be carried in a dry state and be rehydrated upon arrival. Among bacteria that can withstand long-term desiccation, the only species that can currently be genetically engineered belong to this genus (Billi 2010, 2012). Their main drawbacks are their slow growth rates (depending on the strain, their generation time ranges from about 4 to 16 days; see Billi 2010) - a common feature among rockinteracting extremophiles (Cockell 2011) - and, as in the case of Arthrospira spp., their need for fixed N supplementation (a few studies suggest that some strains could fix $\mathrm{N}$ under specific conditions [Boison \& Mergel 2004; Banerjee \& Verma 2009], but this is still to be confirmed). Then, species from the closely related Anabaena and Nostoc genera (see Fig. 7) seem very promising. In addition to their high growth rates (by cyanobacterial standards), they can fix $\mathrm{N}$ and some species have extensive bioleaching abilities (Arai et al. 2008; Olsson-Francis \& Cockell 2010; Olsson-Francis et al. 2012). When cyanobacterium species from different genera were tested for their abilities to grow in distilled water containing only powdered analogues of Mars basaltic rocks, A. cylindrica had the maximum biomass production and the greatest specific growth rate under these conditions (Olsson-Francis \& Cockell 2010). This species also forms akinetes, providing high resistance to simulated Martian surface conditions (Olsson-Francis \& Cockell 2010), to simulated space conditions and to low Earth orbit conditions (Olsson-Francis et al. 2009). Some species are suitable for genetic engineering and Anabaena sp. PCC7120 has already

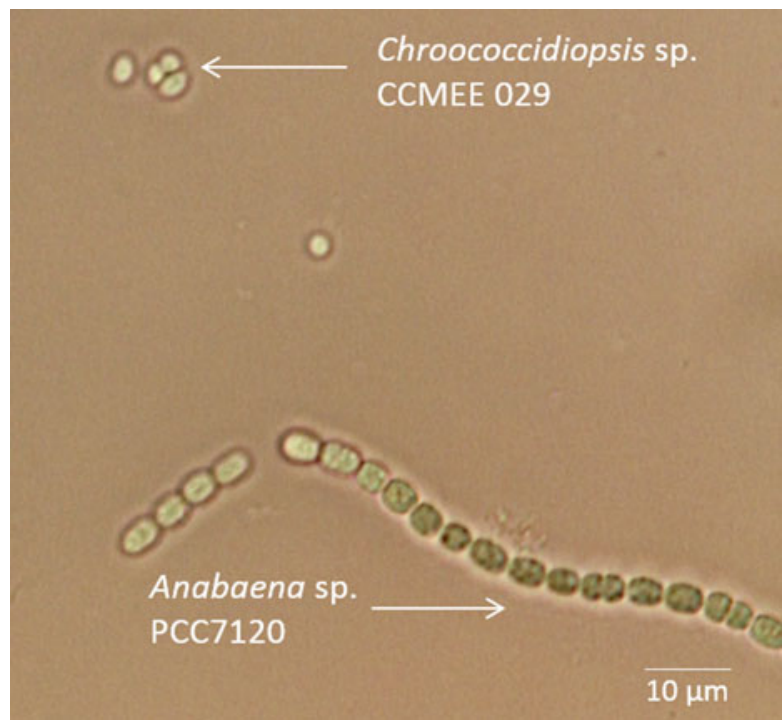

Fig. 7. Two examples of cyanobacteria: Anabaena sp. PCC7120 and Chroococcidiopsis sp. CCMEE 029.

been modified to produce and secrete sucrose, which can be used to sustain the growth of heterotrophic organisms (Stanford-Brown 2011 iGEM team 2011). Several strains, notably $A$. cylindrica, are very efficient $\mathrm{H}_{2}$ producers (Abed et al. 2009). Additionally, some strains are edible: $N$. commune, $N$. flagelliforme and Anabaena spp. in symbiosis with Azolla spp., for instance, are traditionally consumed. Finally, using model cyanobacteria such as Synechocystis spp. and Synechococcus spp. might also be a fruitful approach: their natural metabolic and resistance properties may be less appealing than those of the above-mentioned strains, but their high growth rates, well-characterized metabolism and availability of engineering tools (Berla et al. 2013) could make them relevant chassis organisms, provided extensive engineering is performed. Whether emphasis should be put on extremophile properties or metabolic functions of interest when selecting strains in this context has been questioned. The answer might vary according to the scenario, and stages, of colonization: if protection can be provided at low cost, for instance, the need for resistance is reduced and priority can be given to metabolic functions. It may also depend on the development of our abilities to confer new metabolic pathways on extremophiles and to increase resistance of species of metabolic interest. A summary of the main advantages of the genera mentioned in this paragraph is given in Table 2 . Generally speaking, a relatively low number of cyanobacterium species and strains have been tested so far against factors relevant for BLSS. Systematic tests could point out new candidate species and strains. After and/or in parallel to the selection, genetic engineering can be used to improve the relevance of the strains of interest.

Next, a compromise should be identified between (i) conditions (radiation shielding, atmospheric composition and pressure, gravity, nutrient supply, etc.) optimizing growth and metabolism of the selected microorganisms, and (ii) conditions that depend as much as possible on resources available on site 
Table 2. Examples of cyanobacterial genera of relevance for Mars-specific BLSS

\begin{tabular}{ll}
\hline Genera & Most relevant specific features \\
\hline Arthrospira & $\begin{array}{l}\text { Edible species with excellent nutritional properties; productive under adequate conditions; demanding in terms of culture } \\
\text { conditions }\end{array}$ \\
Cyanothece & $\begin{array}{l}\text { High growth rates; N fixation; suspected edibility } \\
\text { Extremophile; can be stored desiccated for several years; can maintain exogenous plasmids } \\
\text { AnabaenalNostoc }\end{array}$ \\
$\begin{array}{l}\text { N fixation; symbioses with plants; edible species; efficient lithotrophic growth on regolith simulant; efficient molecular } \\
\text { biology tools available; } \mathrm{H}_{2} \text { production; form highly resistant akinetes }\end{array}$ \\
Fynechocystis/ & $\begin{array}{l}\text { Fast-growing; well-studied metabolism; many genetic engineering tools available; efficient growth demonstrated in low } \\
\text { pressure/high } \mathrm{CO}_{2} \text { atmospheres }\end{array}$ \\
\hline
\end{tabular}

and that minimize costs (e.g., low atmospheric pressure mainly composed of $\mathrm{CO}_{2}$ and $\mathrm{N}_{2}$ ). The minimal parameters needed for efficient metabolism of photosynthetic microorganisms remain poorly defined and, even more than extreme values of individual parameters, the effects of their combinations are poorly documented (Harrison et al. 2013). Extensive characterization work is thus needed. More specifically, conditions closest to Martian surface conditions while supporting growth, photosynthetic activity and, for some species, $\mathrm{N}$ fixation and $\mathrm{H}_{2}$ production, should be defined. In particular, the minimal pressure of a gas mixture similar to the Martian atmosphere (possibly enriched in $\mathrm{N}_{2}$, though) which is suitable should be identified. The use of Martian regolith as a nutrient source for all compounds except $\mathrm{C}$ and $\mathrm{N}$ should also be studied in this context, as microorganisms' interactions with minerals are poorly characterized, even in ambient terrestrial environments. It should be noted that suitable culture conditions are expected to be organism- and application-specific and, as described above, all these features could also be increased by genetic engineering. In any case, the genetic stability of the strains of interest under expected culture conditions should be tested to ensure that the efficiency of targeted processes and nutritional properties are not affected in the long term: targeted modifications may be lost (as described in section 'Engineering cyanobacteria'), but mutations can also appear at other genomic loci and spread, even in the absence of a strong selection pressure (e.g., Kanesaki et al. 2012; Trautmann et al. 2012).

Once a compromise between efficient growth and low cost has been identified, culture hardware that can provide the selected conditions directly on Mars's surface, from on-site resources, can be designed. Extensive on-ground testing should be performed to demonstrate operational capability of all the components of the system. A prototype could then be tested for its ability to support the growth of cyanobacteria in the long term in simulated Mars surface conditions

If edible cyanobacteria and plants are to be used as food during Mars missions, whether their nutraceutical properties are affected under the expected conditions should be investigated. A suitable diet could then be designed, which would cover nutritional needs while being psychologically satisfying in the long term. It might involve a combination of processed cyanobacteria and plants to balance protein, carbohydrate and lipid ratios while having a pleasant taste, although adequate processing and genetic modifications of cyanobacteria may make the use of plants unnecessary in this context.

Outputs (biomass, released metals, $\mathrm{O}_{2}$, etc.) under the expected culture conditions should be accurately characterized for a clear vision of the scale needed and to assess the relevance of the system in various mission scenarios, including varying duration of mission and crew size. In particular, it would be useful to determine in which cases this system would be advantageous compared with stored supplies and resupply from Earth. How many resources could be produced, and how many crewmembers could be supported as a function of starting compounds (e.g., regolith amounts, atmospheric gas and culture supplements), initial payload mass, needed cultivation surface, crew-time and energy consumption? Extensive mathematical modelling, including results from laboratory simulations, would be useful. Some physical tests should be conducted on Earth (where the experiment can be stopped in case of a major problem), possibly with isolated crews in Mars analogue sites. However, some of the conditions that will be faced on-site (e.g., reduced gravity and space radiation) cannot be faithfully simulated. In particular, despite giving useful insights, ground-based reduced gravity simulators each have specific artefacts (e.g., centrifugal accelerations of clinostats) and only real spaceflight can be used for unambiguously asserting the effects of reduced gravity on a biological system (Herranz et al. 2013). Testing the components of the system in space, for instance on-board the International Space Station or within commercial satellites, would consequently be an important step in demonstrating the system's feasibility. Some useful regolith simulants are available, but given differences between these and real Martian regolith, validating some aspects of the system (e.g., growth rates while using it as a nutrient source, toxicity, etc.) would ideally be done using real Martian soil, provided sufficient amounts could be brought back by sample return missions.

The investigated processes should obviously not be developed in total isolation, but rather be grounded into broader Mars exploration plans and foreseen technologies. In particular, it seems critical to ensure its compatibility with currently developed life-support systems: since a cyanobacterium-based system could connect on-site resources and BLSS by turning the former into a substrate for the latter, it could be conjugated with advanced BLSS projects (e.g., MELiSSA), making these suitable for a Martian base. Technologies and processes could be developed and tested to make the link between the concepts 
described in this paper and other BLSS projects. For instance, studies could point out the most efficient ways of processing cyanobacterial biomass and released nutrients to feed specific BLSS's plant and microbial modules.

As BLSS for human bases on Mars implies growing living organisms there, planetary protection is a critical concern. The Committee on Space Research (COSPAR)'s requirements for planetary protection need to be extended for manned Mars exploration (Horneck 2008), especially if human colonies rely on microbial cultures for life support and industrial processes. The planetary protection-associated risks of the concepts described above should be thoroughly investigated, and strategies to mitigate these risks developed. The main concern will be to bring contamination risks at regions of scientific interest down to close to zero.

Then, generated data can be gathered to propose an accurate and practical solution for the establishment of BLSS which are suitable for sustainable human outposts on Mars. The next steps will be to integrate this solution into mission plans, to test it on site while backup resources are available, and finally to implement it.

\section{Conclusion}

Advances in applied physics will allow us to step on Mars; advances in applied biology can allow us to settle there.

Landing humans on Mars in the 2020-2030s is targeted by several public and private institutions. NASA's Orion capsule successfully made its first in-space test last December. SpaceX's CEO Elon Musk will unveil his Mars colonization plans by the end of the year. Mars One is in the process of selecting crewmembers. Other institutions might enter this 'Mars race'. But whoever is the first to land, the same issue will have to be faced: if we are to stay on Mars in the long term to obtain valuable scientific data, we need to learn to be independent of Earth. However, while space travel technologies have made great steps forward in the last half century, current life-support technologies are not sufficiently developed for sustaining Mars manned exploratory missions (Horneck et al. 2006). Extensive efforts in this area should start now, so that life support does not become the limiting factor.

Living organisms, wild-type or modified using synthetic biology, are likely to become essential components of lifesupport systems. But in order to be independent of Earth, they should rely almost exclusively on local resources once set up from an initial set of components. Biological systems should be connected to Martian resources and cyanobacteria could provide this link. Selected - and possibly engineered cyanobacteria and an appropriate culture system kept to a minimum thanks to cyanobacteria's adaptability to extreme environmental conditions.

The concepts presented in this paper are not intended as a full life-support system plan. They are rather intended as a proposed link between on-site resources and BLSS, through processing of local materials to make these suitable inputs for BLSS. This basis could be combined to currently developed BLSS, making these sustainable, autonomous and expandable within Mars bases. Efforts can thus be combined rather than duplicated. Basic requirements (e.g., food and $\mathrm{O}_{2}$ ) could also be covered directly by cyanobacterial cultures. Some of these functions could be performed by other means (e.g., physicochemical technologies and cultures of other organisms), but cyanobacteria would provide simple (and consequently characterized by a relatively low number of potential causes of failure) and flexible processes to complement other technologies and provide a safe redundancy. With the extremely fast progress which is being made in microbial engineering, more and more processes needed within Martian outposts could be performed by cyanobacteria. This versatility is a strong advantage when mass and resource use need to be kept to a strict minimum.

Even though the last decades have raised our knowledge in this field, much work is still needed to develop the concepts presented here. How challenging it will be to turn these concepts into reliable systems is currently hard to predict. Firstly, we are still learning about the Martian environment; several parts of this paper had to be modified during the writing process to integrate new inputs from the Curiosity rover. Discovering new factors can make things appear easierfor instance, if organic substrates are discovered to be widely available - or more challenging - for instance, with the discovery of toxic elements. Secondly, the pace at which biology engineering is progressing - not unlike microcomputers in the past 40 years - suggests that unexpected and highly efficient ways of modifying cyanobacteria and other organisms will become available. As we could once have scarcely imagined how much we rely on computers now, engineered biological systems on Mars may be more versatile and important in pioneers' everyday life than we can envisage at present. Our abilities to discover life on Mars might depend on our abilities to handle life on Earth.

\section{Acknowledgements}

The authors are grateful to Sean McMahon (Yale University) for his remarkable artistic rendering. They thank Rocco L. Mancinelli and an anonymous reviewer, whose comments led to significant improvements to the manuscript. They are also grateful to Ivan G. PaulinoLima, Kosuke Fujishima, Ryan Kent, Griffin McCutcheon, Evie Pless, Jesica Navarrete, Diana Gentry and J. Mike Grace (Lynn Rothschild's laboratory, NASA Ames Research Center) for stimulating discussions. Finally, they thank Christiane Heinicke (Aalto University) for proofreading the penultimate version of the manuscript. This work was supported by the Italian Space Agency, noteworthy through their support to the BIOMEX_Cyano and BOSS_Cyano experiments. It was also supported by CV's appointment to the NASA Education Associates Program managed by the Universities Space Research Association. 


\section{References}

Abed, R.M.M., Dobretsov, S. \& Sudesh, K. (2009). Applications of cyanobacteria in biotechnology. J. Appl. Microbiol. 106, 1-12.

Agarwal, R., Rane, S.S. \& Sainis, J.K. (2008). Effects of ${ }^{60} \mathrm{Co} \gamma$ radiation on thylakoid membrane functions in Anacystis nidulans. J. Photochem. Photobiol. 91, 9-19.

Aikawa, S., Joseph, A., Yamada, R., Izumi, Y., Yamagishi, T., Matsuda, F., Kawai, H., Chang, J.-S., Hasunuma, T. \& Kondo, A. (2013). Direct conversion of Spirulina to ethanol without pretreatment or enzymatic hydrolysis processes. Energy Environ. Sci. 6, 1844-1849.

Allen, C.C., Morris, R.V., Lindstrom, D.J., Lindstrom, M.M. \& Lockwood, J.P. (1997). JSC Mars-1: Martian regolith simulant. In Lunar and Planetary Science XXVII, LPI Contribution No. 1593, Houston, TX, id. 1797.

Allen, C.S. et al. (2003). Guidelines and Capabilities for Designing Human Missions (NASA/TM-2003-210785). NASA Johnson Space Center, Houston, TX

Allen, J.L. (1991). Biosphere 2: the Human Experiment. Penguin Books, New York.

Andersson, C.R., Tsinoremas, N.F., Shelton, J., Lebedeva, N.V., Yarrow, J., Min, H. \& Golden, S.S. (2000). Application of bioluminescence to the study of circadian rhythms in cyanobacteria. Methods Enzymol. 305, $527-542$.

Angermayr, S.A., Paszota, M. \& Hellingwerf, K.J. (2012). Engineering a cyanobacterial cell factory for production of lactic acid. Appl. Environ. Microbiol., 78, 7098-7106.

Arai, M., Tomita-Yokotani, K., Sato, S., Hashimoto, H., Ohmori, M. \& Yamashita, M. (2008). Growth of terrestrial cyanobacterium, Nostoc sp., on Martian Regolith Simulant and its vacuum tolerance. Biol. Sci. Space 22, 8-17.

Arvidson, R., Squyres, S. \& Bell, J. (2014). Ancient aqueous environments at Endeavour crater, Mars. Science 343, 1-8.

Asato, Y. (1971). Photorecovery of gamma irradiated cultures of blue-green alga, Anacystis nidulans. Radiat. Bot. 11, 313-316.

Averner, M., Moore, B., Bartholomew, I. \& Wharton, R. (1984). Atmosphere behavior in gas-closed mouse-algal systems: an experimental and modelling study. Adv. Space Res. 4, 231-239.

Badri, H. Monsieurs, P., Coninx, I., Wattiez, R. \& Leys, N. (2015). Molecular investigation of the radiation resistance of edible cyanobacterium Arthrospira sp. PCC 8005. MicrobiologyOpen 4, 187-207.

Bajwa, R., Abuarghub, S. \& Read, D.J. (1985). The biology of Mycorrhiza in the Ericaceae. X. The utilization of proteins and the production of proteolytic enzymes by the mycorrhizal endophyte and by mycorrhizal plants. New Phytol. 101, 469-486.

Baker, D. \& Zubrin, R. (1990). Mars direct: combining near-term technologies to achieve a two-launch manned Mars mission. $J$. Br. Interplanet. Soc. 43, 519-526.

Banerjee, M. \& Verma, V. (2009). Nitrogen fixation in endolithic cyanobacterial communities of the McMurdo Dry Valley, Antarctica. Science Asia 35, 215-219.

Banin, A. (1989). Mars soil - a sterile regolith or a medium for plant growth? In The Case for Mars III, ed. Stoker, C.L., pp. 559-571. Univelt, San Diego, CA.

Baqué, M., de Vera, J.-P., Rettberg, P. \& Billi, D. (2013). The BOSS and BIOMEX space experiments on the EXPOSE-R2 mission: endurance of the desert cyanobacterium Chroococcidiopsis under simulated space vacuum, Martian atmosphere, UVC radiation and temperature extremes. Acta Astronaut. 91, 180-186.

Baqué, M., Verseux, C., Rabbow, E., de Vera, J.-P.P. \& Billi, D. (2014). Detection of maromolecules in desert cyanobacteria mixed with a lunar mineral analogue after space simulations. Orig. Life Evol. Biosph. 44, 209-221.

Barker, A.V. \& Mills, H.A. (1980). Ammonium and nitrate nutrition of horticultural crops. Hort. Rev. 2, 395-423.

Beliaev, A.S. et al. (2014). Inference of interactions in cyanobacterialheterotrophic co-cultures via transcriptome sequencing. ISME J. 8, 2243-2255.
Benoit, M.R. \& Klaus, D.M. (2007). Microgravity, bacteria, and the influence of motility. Adv. Space Res. 39, 1225-1232.

Bentley, F.K., Zurbriggen, A. \& Melis, A. (2014). Heterologous expression of the mevalonic acid pathway in cyanobacteria enhances endogenous carbon partitioning to isoprene. Mol. Plant 7, 71-86.

Bergman, B., Johansson, C. \& Soderback, E. (1992). The Nostoc-Gunnera symbiosis. New Phytol. 122, 379-400.

Berla, B.M., Saha, R., Immethun, C.M., Maranas, C.D., Moon, T.S. \& Pakrasi, H.B. (2013). Synthetic biology of cyanobacteria: unique challenges and opportunities. Front. Microbiol. 4, 246.

Billi, D. (2009). Subcellular integrities in Chroococcidiopsis sp. CCMEE 029 survivors after prolonged desiccation revealed by molecular probes and genome stability assays. Extremophiles 13, 49-57.

Billi, D. (2010). Genetic tools for desiccation- and radiation-tolerant cyanobacteria of the genus Chroococcidiopsis. In Current Research, Technology and Education Topics in Applied Microbiology and Microbial Biotechnology, ed. Méndez-Vilas, A., pp. 1517-1521. Formatex Research Center, Badajoz, Spain.

Billi, D. (2012). Plasmid stability in dried cells of the desert cyanobacterium Chroococcidiopsis and its potential for GFP imaging of survivors on Earth and in space. Orig. Life Evol. Biosph. 42, 235-245.

Billi, D., Friedmann, E.I., Hofer, K.G., Caiola, M.G. \& Ocampo-Friedmann, R. (2000a). Ionizing-radiation resistance in the desiccation-tolerant cyanobacterium Chroococcidiopsis. Appl. Environ. Microbiol. 66, 1489-1492.

Billi, D., Wright, D.J., Helm, R.F., Prickett, T., Potts, M. \& Crowe, J.H. (2000b). Engineering desiccation tolerance in Escherichia coli. Appl. Environ. Microbiol. 66, 1680-1684.

Billi, D., Baqué, M., Smith, H. \& McKay, C. (2013). Cyanobacteria from extreme deserts to space. Adv. Microbiol. 3, 80-86.

Bloom, A.J., Sukrapanna, S.S. \& Warner, R.L. (1992). Root respiration associated with ammonium and nitrate absorption and assimilation by barley. Plant Physiol. 99, 1294-1301.

Blüm, V., Gitelson, J., Horneck, G. \& Kreuzberg, K. (1994). Opportunities and constraints of closed man-made ecological systems on the moon. Adv. Space Res. 14, 271-280.

Boison, G. \& Mergel, A. (2004). Bacterial life and dinitrogen fixation at a gypsum rock. Appl. Environ. Microbiol. 70, 7070-7077.

Bonham, K. \& Palumbo, R.F. (1951). Effects of x-rays on snails, crustacea, and algae. Growth 15, 155-168.

Böttger, U., de Vera, J.-P., Fritz, J., Weber, I., Hübers, H.-W. \& Schulze-Makuch, D. (2012). Optimizing the detection of carotene in cyanobacteria in a Martian regolith analogue with a Raman spectrometer for the ExoMars mission. Planet. Space Sci. 60, 356-362.

Boxe, C.S., Hand, K.P., Nealson, K.H., Yung, Y.L. \& Saiz-Lopez, A. (2012). An active nitrogen cycle on Mars sufficient to support a subsurface biosphere. Int. J. Astrobiol. 11, 109-115.

Boynton, W.V.et al. (2007). Concentration of $\mathrm{H}, \mathrm{Si}, \mathrm{Cl}, \mathrm{K}, \mathrm{Fe}$, and $\mathrm{Th}$ in the low- and mid-latitude regions of Mars. J. Geophys. Res.: Planets 112, E12.

Britto, D.T. \& Kronzucker, H.J. (2002). $\mathrm{NH}_{4}^{+}$toxicity in higher plants: a critical review. J. Plant Physiol. 159, 567-584.

Brown, I.I. (2008a). Cyanobacteria to Link Closed Ecological Systems and In-Situ Resources Utilization Processes. In 37th COSPAR Scientific Assembly, Montréal, Canada, p. 383.

Brown, I.I. (2008b). Mutant strains of Spirulina (Arthrospira) platensis to increase the efficiency of micro-ecological life support systems. In 37 th COSPAR Scientific Assembly, Montréal, Canada, p. 384.

Brown, I.I. \& Sarkisova, S. (2008). Bio-weathering of lunar and Martian rocks by cyanobacteria: a resource for Moon and Mars exploration. In Lunar and Planetary Sciences XXXIX, pp. 1-2.

Brown, I.I., Garrison, D.H., Jones, J.A., Allen, C.C., Sanders, G., Sarkisova, S.A. \& McKay, D.S. (2008). The Development and Perspectives of Bio-ISRU. In Joint Annual Meeting of LEAG-ICEUM-SRR, Cape Canaveral, Florida, p. 4048.

Bruce, A.K. (1964). Extraction of the radioresistant factor of Micrococcus radiodurans. Radiat. Res. 22, 155-164. 
Cao, G., Concas, A., Corrias, G., Licheri, R., Orru', R. \& Pisu, M. (2014). Process for the production of useful materials for sustaining manned space missions on Mars through in-situ resources utilization. US Patent Application US 2014/016546 A1.

Chaurasia, A.K., Parasnis, A. \& Apte, S.K. (2008). An integrative expression vector for strain improvement and environmental applications of the nitrogen fixing cyanobacterium, Anabaena sp. strain PCC7120. J. Microbiol. Methods 73, 133-141.

Chen, Y.-C. (2001). Immobilized microalga Scenedesmus quadricauda (Chlorophyta, Chlorococcales) for long-term storage and for application for water quality control in fish. Aquaculture 195, 71-80.

Christensen, P.R. et al. (2001). Mars Global Surveyor Thermal Emission Spectrometer experiment: investigation description and surface science results. J. Geophys. Res. 106, 23823-23871.

Clapp, M. (1985). Water supply for a manned Mars base. In The Case for Mars II, ed. McKay, C.P., pp. 557-566. Univelt, San Diego, CA.

Clark, B.C., Baird, A.K., Weldon, R.J., Tsusaki, D.M., Schnabel, L. \& Candelaria, M.P. (1982). Chemical composition of Martian fines. J. Geophys. Res. Solid Earth 87, 10059-10067.

Clerico, E.M., Ditty, J.L. \& Golden, S.S. (2007). Specialized techniques for site-directed mutagenesis in cyanobacteria. Methods Mol. Biol. 362, $155-171$.

Clifford, S.M., Lasue, J., Heggy, E., Boisson, J., McGovern, P. \& Max, M.D. (2010). Depth of the Martian cryosphere: revised estimates and implications for the existence and detection of subpermafrost groundwater. J. Geophys. Res. 115, E07001.

Cockell, C.S. (2010). Geomicrobiology beyond Earth: microbe-mineral interactions in space exploration and settlement. Trends Microbiol. 18, 308-314.

Cockell, C.S. (2011). Synthetic geomicrobiology: engineering microbemineral interactions for space exploration and settlement. Int. J. Astrobiol. 10, 315-324.

Cockell, C.S. (2014). Trajectories of Martian habitability. Astrobiology 14, 182-203.

Cockell, C.S., Catling, D.C., Davis, W.L., Snook, K., Kepner, R.L., Lee, P. \& McKay, C.P. (2000). The ultraviolet environment of Mars: biological implications past, present, and future. Icarus 146, 343-359.

Cockell, C.S. \& Raven, J.A. (2004). Zones of photosynthetic potential on Mars and the early Earth. Icarus 169, 300-310.

Cockell, C.S., Rettberg, P., Rabbow, E. \& Olsson-Francis, K. (2011) Exposure of phototrophs to 548 days in low Earth orbit: microbial selection pressures in outer space and on early earth. ISME J. 5, 1671-1682.

Coffin, R.B. (1989). Bacterial uptake of dissolved free and combined amino acids in estuarine waters. Limnol. Oceanogr. 34, 531-542.

Conrad, T. (2011). Microbial laboratory evolution in the era of genome-scale science. Mol. Syst. Biol. 7, 509

Coons, S., Williams, J. \& Bruckner, A. (1997). Feasibility study of water vapor adsorption on Mars for in situ resource utilization. In $33^{\text {rd }}$ Joint Propulsion Conf. and Exhibit, Seattle, WA, AIAA 97-2765.

Crawford, C.C., Hobbie, J.E. \& Webb, K.L. (1974). The utilization of dissolved free amino acids by estuarine microorganisms. Ecology 55, $551-563$.

Cumbers, J. \& Rothschild, L.J. (2010). BISRU: synthetic microbes for Moon, Mars and beyond. In Astrobiology Science Conf. 2010, LPI Contribution No. 1538, League City, TX, id. 5672.

Dahlgren, R., Shoji, S. \& Nanzyo, M. (1993). Mineralogical characteristics of volcanic ash soils. In Volcanic Ash Soils - Genesis, Properties and Utilization, ed. Shoji, S. \& Nanzyo, M., pp. 101-143. Elsevier Science Ltd, Amsterdam.

Dalton, B. \& Roberto, F. (2008). Lunar Regolith Biomining: Workshop Report (NASA/CP-2008-214564). NASA Ames Research Center, Moffett Field, CA

Danin, A., Dor, I., Sandler, A. \& Amit, R. (1998). Desert crust morphology and its relations to microbiotic succession at Mt. Sedom, Israel. J. Arid Environ. 38, 161-174.

Dartnell, L.R. \& Patel, M.R. (2014). Degradation of microbial fluorescence biosignatures by solar ultraviolet radiation on Mars. Int. J. Astrobiol. 13, $112-123$.
Dartnell, L.R., Desorgher, L., Ward, J.M. \& Coates, A.J. (2007). Modelling the surface and subsurface Martian radiation environment: implications for astrobiology. Geophys. Res. Lett. 34, L02207.

de Crecy, E., Jaronski, S., Lyons, B., Lyons, T.J. \& Keyhani, N.O. (2009). Directed evolution of a filamentous fungus for thermotolerance. $B M C$ Biotechnol. 9, 74.

de la Torre, J.R., Goebel, B.M., Friedmann, E.I. \& Pace, N.R. (2003). Microbial diversity of cryptoendolithic communities from the McMurdo Dry Valleys, Antarctica. Appl. Environ. Microbiol. 69, 3858-3867.

Deng, M.D. \& Coleman, J.R. (1999). Ethanol synthesis by genetic engineering in cyanobacteria. Appl. Environ. Microbiol. 65, 523-528.

de Vera, J.-P., Schulze-Makuch, D., Khan, A., Lorek, A., Koncz, A., Möhlmann, D. \& Spohn, T. (2014). Adaptation of an Antarctic lichen to Martian niche conditions can occur within 34 days. Planet. Space Sci. 98, 182-190.

Dexter, J. \& Fu, P. (2009). Metabolic engineering of cyanobacteria for ethanol production. Energy Environ. Sci. 2, 857.

Dienst, D., Georg, J., Abts, T., Jakorew, L., Kuchmina, E., Börner, T., Wilde, A., Dühring, U., Enke, H. \& Hess, W.R. (2014). Transcriptomic response to prolonged ethanol production in the cyanobacterium Synechocystis sp. PCC6803. Biotechnol. Biofuels 7, 21.

Dismukes, G.C., Carrieri, D., Bennette, N., Ananyev, G.M. \& Posewitz, M.C. (2008). Aquatic phototrophs: efficient alternatives to land-based crops for biofuels. Curr. Opin. Biotechnol. 19, 235-240.

Domain, F., Houot, L., Chauvat, F. \& Cassier-Chauvat, C. (2004). Function and regulation of the cyanobacterial genes lexA, recA and ruvB: LexA is critical to the survival of cells facing inorganic carbon starvation. Mol. Microbiol. 53, 65-80.

Drake, B.G. (ed.) (2009). Human Exploration of Mars: Design Reference Architecture 5.0 (NASA-SP-2009-566). NASA Johnson Space Center, Houston, TX

Drysdale, A., Ewert, M. \& Hanford, A. (2003). Life support approaches for Mars missions. Adv. Space Res. 31, 51-61.

Drysdale, A., Nakamura, T., Yorio, N., Sager, J. \& Wheeler, R. (2008). Use of sunlight for plant lighting in a bioregenerative life support system - equivalent system mass calculations. Adv. Space Res. 42, 19291943.

Drysdale, A.E., Rutkze, C.J., Albright, L.D. \& LaDue, R.L. (2004). The minimal cost of life in space. Adv. Space Res. 34, 1502-1508.

Ducat, D.C., Way, J.C. \& Silver, P.A. (2011). Engineering cyanobacteria to generate high-value products. Trends Biotechnol. 29, 95-103.

Dykhuizen, D.E. (1993). Chemostats used for studying natural selection and adaptive evolution. Methods Enzymol. 224, 613-631.

Eldridge, D. \& Greene, R. (1994). Microbiotic soil crusts-a review of their roles in soil and ecological processes in the rangelands of Australia. Soil Res. 32, 389-415.

Elena, S.F. \& Lenski, R.E. (2003). Evolution experiments with microorganisms: the dynamics and genetic bases of adaptation. Nat. Rev. Genet. 4, 457-469.

Ellis, D.I. \& Goodacre, R. (2012). Metabolomics-assisted synthetic biology. Curr. Opin. Biotechnol. 23, 22-28.

Ethridge, E.C. \& Kaulker, W.F. (2012). Microwave extraction of volatiles for Mars science and ISRU. In Concepts and Approaches for Mars Exploration, LPI Contribution No. 1679, Houston, TX, id. 4328.

Ewing, D. (1995). The directed evolution of radiation resistance in E. coli. Biochem. Biophys. Res. Commun. 2, 549-553.

Fajardo-Cavazos, P., Waters, S.M., Schuerger, A.C., George, S., Marois, J.J. \& Nicholson, W.L. (2012). Evolution of Bacillus subtilis to enhanced growth at low pressure: up-regulated transcription of des-desKR, encoding the fatty acid desaturase system. Astrobiology 12, 258-270.

Ferrer, M., Chernikova, T.N., Yakimov, M.M., Golyshin, P.N. \& Timmis, K.N. (2003). Chaperonins govern growth of Escherichia coli at low temperatures. Nat. Biotechnol. 21, 1266-1267.

Filali, R., Lasseur, C. \& Dubertret, G. (1997). MELiSSA: nitrogen sources for growth of the cyanobacterium Spirulina. In Proc. Sixth European Symp. on Space Environmental Control Systems, Noordwijk, The Netherlands, pp. 909-912. 
Finney, L.A. \& O'Halloran, T.V. (2003). Transition metal speciation in the cell: insights from the chemistry of metal ion receptors. Science $\mathbf{3 0 0}$, 931-936.

Friedmann, E.I. \& Ocampo, R. (1976). Endolithic blue-green algae in the Dry Valleys: primary producers in the Antarctic desert ecosystem. Science $\mathbf{1 9 3}$ 1247-1249.

Gao, G., Tian, B., Liu, L., Sheng, D., Shen, B. \& Hua, Y. (2003). Expression of Deinococcus radiodurans PprI enhances the radioresistance of Escherichia coli. DNA Repair 2, 1419-1427.

Giacomelli, G. et al. (2012). Bio-regenerative life support system development for Lunar/Mars habitats. In 42nd Int. Conf. on Environmental Systems, San Diego, CA.

Gitelson, I., Lisovsky, G. \& MacElroy, R. (2003). Manmade Closed Ecological Systems. Taylor \& Francis, London and New York.

Gitelson, J. (1992). Biological life-support systems for Mars mission. Adv. Space Res. 12, 167-192.

Godia, F., Albiol, J., Montesinos, J. \& Pérez, J. (2002). MELISSA: a loop of interconnected bioreactors to develop life support in space. J. Biotechnol. 99, 319-330

Godlewski, M. \& Adamczyk, B. (2007). The ability of plants to secrete proteases by roots. Plant Physiol. Biochem. 45, 657-664.

Godward, M.B.E. (1962). Invisible radiations. In Physiology and Biochemistry of Algae, ed. Lewin, R.A., pp. 551-566. Academic Press, New York.

Goldman, R.P. \& Travisano, M. (2011). Experimental evolution of ultraviolet radiation resistance in Escherichia coli. Evolution 65, 34863498.

Gómez-Elvira, J. et al. (2014). Curiosity's Rover Environmental Monitoring Station: overview of the first 100 sols. J. Geophys. Res.: Planets 119, 16801688.

Grace, J.M., Verseux, C., Gentry, D., Moffet, A., Thayabaran, R., Wong, N. \& Rothschild, L. (2013). Elucidating microbial adaptation dynamics via autonomous exposure and sampling. In AGU Fall Meeting Abstracts, San Francisco, CA, p. 597.

Graham, J.M. (2004). The biological terraforming of Mars: planetary ecosynthesis as ecological succession on a global scale. Astrobiology $\mathbf{4}$ 168-195.

Griese, M., Lange, C. \& Soppa, J. (2011). Ploidy in cyanobacteria. FEMS Microbiol. Lett. 323, 124-131.

Grotzinger, J.P. et al. (2014). A habitable fluvio-lacustrine environment at Yellowknife Bay, Gale crater, Mars. Science 343, 1242777.

Grover, M.R. \& Bruckner, A.P. (1998). Water vapor extraction from the Martian atmosphere by adsorption in molecular sieves. In 34th AIAA/ ASME/SAE/ASEE Joint Propulsion Conf., Cleveland, OH, AAIA 983302.

Guerrero, F., Carbonell, V., Cossu, M., Correddu, D. \& Jones, P.R. (2012). Ethylene synthesis and regulated expression of recombinant protein in Synechocystis sp. PCC 6803. PLoS ONE 7, e50470.

Gusev, M.V., Baulina, O.I., Gorelova, O.A., Lobakova, E.S. \& Korzhenevskaya, T.G. (2002). Artificial cyanobacterium-plant symbioses. In Cyanobacteria in Symbiosis, ed. Rai, A.N., Bergman, B. \& Rasmussen, U., pp. 253-312. Springer, The Netherlands.

Harris, D.R. et al. (2009). Directed evolution of ionizing radiation resistance in Escherichia coli. J. Bacteriol. 191, 5240-5252.

Harrison, J.P., Gheeraert, N., Tsigelnitskiy, D. \& Cockell, C.S. (2013). The limits for life under multiple extremes. Trends Microbiol. 21, 204-212.

Hassler, D.M. et al. (2013). Mars' surface radiation environment measured with the Mars Science Laboratory's Curiosity rover. Science 343, 1244797.

Heap, J.T., Ehsaan, M., Cooksley, C.M., Ng, Y.K., Cartman, S.T., Winzer, K. $\&$ Minton, N.P. (2012). Integration of DNA into bacterial chromosomes from plasmids without a counter-selection marker. Nucleic Acids Res. 40, e59.

Hecht, M.H. et al. (2009). Detection of perchlorate and the soluble chemistry of Martian soil at the Phoenix lander site. Science 325, 64-67.

Hendrickx, L. \& Mergeay, M. (2007). From the deep sea to the stars: human life support through minimal communities. Curr. Opin. Microbiol. 10, 231-237.

Hendrickx, L., De Wever, H., Hermans, V., Mastroleo, F., Morin, N., Wilmotte, A., Janssen, P. \& Mergeay, M. (2006). Microbial ecology of the closed artificial ecosystem MELiSSA (Micro-Ecological Life Support System Alternative): reinventing and compartmentalizing the Earth's food and oxygen regeneration system for long-haul space exploration missions. Res. Microbiol. 157, 77-86.

Henrikson, R. (2009). Earth Food Spirulina, Revised ed. Ronore Enterprises, Inc., Hana, Maui, HI.

Herranz, R. et al. (2013). Ground-based facilities for simulation of microgravity: organism-specific recommendations for their use, and recommended terminology. Astrobiology 13, 1-17.

Herrera, A., Cockell, C.S., Self, S., Blaxter, M., Reitner, J., Thorsteinsson, T., Arp, G., Dröse, W. \& Tindle, A.G. (2009). A cryptoendolithic community in volcanic glass. Astrobiology 9, 369-381.

Herrero, M., De Lorenzo, V. \& Timmis, K.N. (1990). Transposon vectors containing non-antibiotic resistance selection markers for cloning and stable chromosomal insertion of foreign genes in gram-negative bacteria. J. Bacteriol. 172, 6557-6567.

Hertzberg, S. \& Jensen, A. (1989). Studies of alginate immobilized marine microalgae. Bot. Marina 32, 267-274.

Hoffman, S.J. \& Kaplan, D.I. (1997). Human Exploration of Mars: the Reference Mission of the NASA Mars Exploration Study Team (NASA Special Publication 6107). NASA Johnson Space Center, Houston, TX.

Hollibaugh, J.T. \& Azam, F. (1983). Microbial degradation of dissolved proteins in seawater. Limnol. Oceanogr. 28, 1104-1116.

Horneck, G. (2008). The microbial case for Mars and its implication for human expeditions to Mars. Acta Astronaut. 63, 1015-1024.

Horneck, G. et al. (2003). HUMEX, a study on the survivability and adaptation of humans to long-duration exploratory missions, part I: lunar missions. Adv. Space Res. 31, 2389-2401.

Horneck, G. et al. (2006). HUMEX, a study on the survivability and adaptation of humans to long-duration exploratory missions, part II: missions to Mars. Adv. Space Res. 38, 752-759.

Horneck, G., Klaus, D.M. \& Mancinelli, R.L. (2010). Space microbiology. Microbiol. Mol. Biol. Rev. 74, 121-156.

Hoshino, K., Hamochi, M., Mitsuhashi, S. \& Tanishita, K. (1991). Measurements of oxygen production rate in flowing. Appl. Microbiol. Biotechnol. 35, 89-93.

Howitt, S.M. \& Udvardi, M.K. (2000). Structure, function and regulation of ammonium transporters in plants. Biochim. Biophys. Acta-Biomembranes $1465,152-170$.

Jack, D.A., Nakamura, T., Sadler, P. \& Cuello, J.L. (2002). Evaluation of two fiber optic-based solar collection and distribution systems for advanced space life support. Trans. ASAE 45, 1547-1558.

Jiménez, C., Cossío, B.R. \& Niella, F.X. (2003). Relationship between physicochemical variables and productivity in open ponds for the production of Spirulina: a predictive model of algal yield. Aquaculture 221, 331-345.

Jones, P.R. (2014). Genetic instability in cyanobacteria - an elephant in the room? Front. Bioeng. Biotechnol. 2, Art. 12.

Kanervo, E., Lehto, K., Ståhle, K., Lehto, H. \& Mäenpää, P. (2005). Characterization of growth and photosynthesis of Synechocystis sp. PCC 6803 cultures under reduced atmospheric pressures and enhanced $\mathrm{CO}_{2}$ levels. Int. J. Astrobiol. 4, 97.

Kanesaki, Y., Shiwa, Y., Tajima, N., Suzuki, M., Watanabe, S., Sato, N., Ikeuchi, M. \& Yoshikawa, H. (2012). Identification of substrain-specific mutations by massively parallel whole-genome resequencing of synechocystis sp. PCC 6803. DNA Res. 19, 67-79.

Kim, M., Zhang, Z., Okano, H., Yan, D., Groisman, A. \& Hwa, T. (2012). Need-based activation of ammonium uptake in Escherichia coli. Mol. Syst. Biol. 8, 616.

Kirensky, L.V, Terskov, I.A., Gitelson, I.I., Lisovsky, G.M., Kovrov, B.G. \& Okladnikov, Y.N. (1968). Experimental biological life support system. II. Gas exchange between man and microalgae culture in a 30-day experiment. Life Sci. Space Res. 6, 37-40.

Klingler, J.M., Mancinelli, R.L. \& White, M.R. (1989). Biological nitrogen fixation under primordial Martian partial pressures of dinitrogen. Adv. Space Res. 9, 173-176.

Koksharova, O. \& Wolk, C. (2002). Genetic tools for cyanobacteria. Appl. Microbiol. Biotechnol. 58, 123-137. 
Kozyrovska, N. et al. (2006). Growing pioneer plants for a lunar base. $A d v$. Space Res. 37, 93-99.

Kral, T., Altheide, T.S., Lueders, A.E. \& Schuerger, A.C. (2011). Low pressure and desiccation effects on methanogens: implications for life on Mars. Planet. Space Sci. 59, 264-270.

Kraus, M.P. (1969). Resistance of blue-green algae to ${ }^{60} \mathrm{Co}$ gamma radiation. Radiat. Bot. 9, 481-489.

Kudenko, Y. A., Gribovskaya, I.V. \& Zolotukhin, I.G. (2000). Physicalchemical treatment of wastes: a way to close turnover of elements in LSS. Acta Astronaut. 46, 585-589.

Kumar, H.D. (1964). Effects of radiations on blue-green algae II: effects on growth. Annal. Bot. 28, 555-564.

Kurahashi-Nakamura, T. \& Tajika, E. (2006). Atmospheric collapse and transport of carbon dioxide into the subsurface on early Mars. Geophys. Res. Lett. 33, L18205.

Langevin, Y., Poulet, F., Bibring, J.-P. \& Gondet, B. (2005). Sulfates in the north polar region of Mars detected by OMEGA/Mars Express. Science 307, 1584-1586.

Langhoff, S., Cumbers, J., Rothschild, L.J., Paavola, C. \& Worden, S.P. (2011). What are the Potential Roles for Synthetic Biology in NASA's Mission? (NASA/CP-2011-216430). NASA Ames Research Center, Moffett Field, CA.

Latshaw, W.L. \& Miller, E.C. (1934). Elemental composition of the corn plant. J. Agric. Res. 27, 845-861.

Lee, S.Y. (2012). Metabolic engineering and synthetic biology in strain development. ACS Synth. Biol. 1, 491-492.

Lehto, K., Kanervo, E., Stahle, K. \& Lehto, H. (2007). Photosynthetic life support systems in the Martian conditions. In ROME: Response of Organisms to the Martian Environment (ESA AP-1299), ed. Cockell, C. \& Horneck, G., pp. 151-160. ESA Communications, Noordwijk, The Netherlands.

Lehto, K.M., Lehto, H.J. \& Kanervo, E.A. (2006). Suitability of different photosynthetic organisms for an extraterrestrial biological life support system. Res. Microbiol. 157, 69-76.

Le Postollec, A. et al. (2009). Monte Carlo simulation of the radiation environment encountered by a biochip during a space mission to Mars. Astrobiology 9, 311-323.

Lipson, D. \& Näsholm, T. (2001). The unexpected versatility of plants: organic nitrogen use and availability in terrestrial ecosystems. Oecologia 128, 305-316.

Liu, J., Bukatin, V.E. \& Tsygankov, A.A. (2006). Light energy conversion into $\mathrm{H}_{2}$ by Anabaena variabilis mutant PK84 dense cultures exposed to nitrogen limitations. Int. J. Hydrog. Energy 31, 1591-1596.

Liu, Y., Cockell, C.S., Wang, G., Hu, C., Chen, L. \& De Philippis, R. (2008). Control of Lunar and Martian dust - experimental insights from artificial and natural cyanobacterial and algal crusts in the desert of Inner Mongolia, China. Astrobiology 8, 75-86.

Lobascio, C., Lamantea, M., Cotronei, V., Negri, B., De Pascale, S., Maggio, A., Foti, M. \& Palumberi, S. (2007). Plant bioregenerative life supports: The Italian CAB Project. J. Plant Interact. 2, 125-134.

Lukavský, J. (1988). Long-term preservation of algal strains by immobilization. Archiv für Protistenkunde 135, 65-68.

Madigan, M.T., Martinko, J.M. \& Parker, J. (2000). Brock Biology of Microorganisms, 9th edn. Prentice Hall, Upper Saddle River, NJ.

Maggi, F. \& Pallud, C. (2010). Space agriculture in micro- and hypo-gravity: a comparative study of soil hydraulics and biogeochemistry in a cropping unit on Earth, Mars, the Moon and the space station. Planet. Space Sci. 58, 1996-2007.

Mancinelli, R.L. \& Banin, A. (2003). Where is the nitrogen on Mars? Int. J. Astrobiol. 2, 217-225.

Mancinelli, R.L. \& Klovstad, M. (2000). Martian soil and UV radiation: microbial viability assessment on spacecraft surfaces. Planet. Space Sci. 48, 1093-1097.

Marlière, P., Patrouix, J., Döring, V., Herdewijn, P., Tricot, S., Cruveiller, S., Bouzon, M. \& Mutzel, R. (2011). Chemical evolution of a bacterium's genome. Angew. Chem. 50, 7109-7114.

Martín-Torres, F.J. et al. (2015). Transient liquid water and water activity at Gale Crater on Mars. Nat. Geosci. 8, 357-361.
Massa, G.D., Emmerich, J.C., Morrow, R.C., Bourget, C.M. \& Mitchell, C.A. (2007). Plant-growth lighting for space life support: a review. Gravit. Space Biol. 19, 19-30.

Matsuoka, M., Takahama, K. \& Ogawa, T. (2001). Gene replacement in cyanobacteria mediated by a dominant streptomycin-sensitive rps 12 gene that allows selection of mutants free from drug resistance markers. Microbiology 147, 2077-2087.

McEwen, A.S., Ojha, L., Dundas, C.M., Mattson, S.S., Byrne, S., Wray, J.J., Cull, S.C., Murchie, S.L., Thomas, N. \& Gulick, V.C. (2011). Seasonal flows on warm Martian slopes. Science 333, 740-743.

McFall, E. \& Newman, E.B. (1996). Amino acids as carbon sources. In Escherichia coli and Salmonella: Cellular and Molecular Biology, ed. Neidhardt, F.C., Curtiss, R. III, Ingraham, J.L., Lin, E.C.C., Low, K. B., Magasanik, B., Reznikoff, W.S., Riley, M., Schaechter, M. \& Umbarger, H.E., pp. 358-379. ASM Press, Washington, DC.

McKay, C.P. \& Marinova, M. (2001). The physics, biology, and environmental ethics of making Mars habitable. Astrobiology 1, 89-110.

McKay, C.P., Meyer, T.R., Boston, P.J., Nelson, M. \& McCallum, T. (1993). Utilizing Martian resources for life support. In Resources of Near Earth Space, ed. Lewis, J.S., Matthews, M.S. \& Guerrieri, M.L., pp. 819-843. The Arizona Board of Regents, Tucson, AZ.

McKay, D.S. \& Allen, C.C. (1996). Concrete - a practical construction material for Mars. In Proc. of the Fifth International Conf. on Engineering, Construction, and Operations in Space, Albuquerque, NM, pp. 566-570.

McLennan, S.M. et al. (2014). Elemental geochemistry of sedimentary rocks at Yellowknife Bay, Gale crater, Mars. Science 343, 1244734.

McMahon, S., Parnell, J., Ponicka, J., Hole, M. \& Boyce, A. (2013). The habitability of vesicles in Martian basalt. Astron. Geophys. 54, 17-21.

McSween, H.Y. (1994). What we have learned about Mars from SNC meteorites. Meteoritics 29, 757-779.

McSween, H.Y., Taylor, G.J. \& Wyatt, M.B. (2009). Elemental composition of the Martian crust. Science 324, 73673-73679.

Menezes, A.A., Cumbers, J., Hogan, J.A. \& Arkin, A.P. (2014). Towards synthetic biological approaches to resource utilization on space missions. J. R. Soc. Interface 12, 20140715.

Meyer, T.R. \& McKay, C.P. (1984). The atmosphere of Mars-resources for the exploration and settlement of Mars. In The Case for Mars, ed. Boston, P.J., pp. 209-232. Univelt, San Diego, CA.

Meyer, T.R. \& McKay, C.P. (1989). The resources of Mars for human settlement. J. Br. Interplanet. Soc. 42, 147-160.

Meyer, T.R. \& McKay, C.P. (1996). Using the resources of Mars for human settlement. In Strategies for Mars: A Guide to Human Exploration, ed. Stoker, C.R. \& Emmart, C., pp. 393-442. Univelt, San Diego, CA.

Miao, X., Wu, Q., Wu, G. \& Zhao, N. (2003). Sucrose accumulation in salt-stressed cells of agp gene deletion-mutant in cyanobacterium Synechocystis sp. PCC 6803. FEMS Microbiol. Lett. 218, 71-77.

Ming, D.W. et al. (2014). Volatile and organic compositions of sedimentary rocks in Yellowknife Bay, Gale crater, Mars. Science 343, 124526.

Möllers, K.B., Cannella, D., Jørgensen, H. \& Frigaard, N.-U. (2014). Cyanobacterial biomass as carbohydrate and nutrient feedstock for bioethanol production by yeast fermentation. Biotechnol. Biofuels 7, 64 .

Montague, M., McArthur, G.H., Cockell, C.S., Held, J., Marshall, W., Sherman, L.A., Wang, N., Nicholson, W.L., Tarjan, D.R. \& Cumbers, J. (2012). The role of synthetic biology for in situ resource utilization (ISRU). Astrobiology 12, 1135-1142.

Mori, K., Ohya, H., Matsumoto, K. \& Furune, H. (1987). Sunlight supply and gas exchange systems in the microalgal bioreactor. Adv. Space Res. 7, 47-52.

Morris, R.V. et al. (2004). Mineralogy at Gusev Crater from the Mössbauer spectrometer on the Spirit Rover. Science 305, 833-836.

Mueller, R.P. \& Van Susante, P.J. (2011). A review of Lunar regolith excavation robotic device prototypes. In American Institute of Aeronautics and Astronautics Space 2011 Conf., Long Beach, CA, Paper \# 1073752.

Muhlestein, D.J., Hooten, T.M., Koenig, R., Grossl, P. \& Bugbee, B. (1999). Is nitrate necessary to biological life support? In The Int. Conf. on Environmental Systems (ICES) Meeting, Denver, CO, pp. 2-5. 
Murphy, R.C., Gasparich, G.E., Bryant, D.A. \& Porter, R.D. (1990). Nucleotide sequence and further characterization of the Synechococcus sp. strain PCC 7002 recA gene: complementation of a cyanobacterial recA mutation by the Escherichia coli recA gene. J. Bacteriol. 172, 967976.

Murukesan, G., Leino, H., Mäenpää, P., Stahle, K., Raksajit, W., Lehto, H., Allahverdiyeva-Rinne, Y. \& Lehto, K. (2015). Pressurized Martian-like pure $\mathrm{CO}_{2}$ atmosphere supports strong growth of cyanobacteria, and causes significant changes in their metabolism. Orig. Life Evol. Biosph., in press.

Mustard, J.F. et al. (2008). Hydrated silicate minerals on Mars observed by the Mars Reconnaissance Orbiter CRISM instrument. Nature 454, 305-309.

Nakamura, T., Van Pelt, A.D., Yorio, N.C., Drysdale, A.E., Wheeler, R.M. \& Sager, J.C. (2009). Transmission and distribution of Photosynthetically Active Radiation (PAR) from solar and electric light sources. Habitation 12, 103-117.

Näsholm, T., Kielland, K. \& Ganeteg, U. (2009). Uptake of organic nitrogen by plants. New Phytol. 182, 31-48.

Navarrete, J.U., Cappelle, I.J., Schnittker, K. \& Borrok, D.M. (2012). Bioleaching of ilmenite and basalt in the presence of iron-oxidizing and iron-scavenging bacteria. Int. J. Astrobiol. 12, 123-134.

Nelson, M., Dempster, W.F. \& Allen, J.P. (2008). Integration of lessons from recent research for "Earth to Mars" life support systems. Adv. Space Res. 41, 675-683.

Nelson, M., Pechurkin, N.S., Allen, J.P., Somova, L.A. \& Gitelson, J.I. (2010). Closed ecological systems, space life support and biospherics. In Handbook of Environmental Engineering, Volume 10: Environmental Biotechnology, ed. Wang, L.K., Ivanov, V., Tay, J.-H. \& Hung, Y.-T., pp. 517-565. Humana Press, New York.

Nicholson, W.L., Fajardo-Cavazos, P., Fedenko, J., Ortíz-Lugo, J.L., Rivas-Castillo, A., Waters, S.M. \& Schuerger, A.C. (2010). Exploring the low-pressure growth limit: evolution of Bacillus subtilis in the laboratory to enhanced growth at 5 kilopascals. Appl. Environ. Microbiol. 76, 7559-7565.

Nicholson, W.L., Krivushin, K., Gilichinsky, D. \& Schuerger, A.C. (2013). Growth of Carnobacterium spp. from permafrost under low pressure, temperature, and anoxic atmosphere has implications for Earth microbes on Mars. Proc. Natl. Acad. Sci. U.S.A. 110, 666-671.

Nickerson, C.A., Mark Ott, C., Mister, S.J., Morrow, B.J., Burns-Keliher, L. \& Pierson, D.L. (2000). Microgravity as a novel environmental signal affecting Salmonella enterica serovar Typhimurium virulence. Infect. Immun. 68, 3147-3152.

Niederholtmeyer, H., Wolfstädter, B.T., Savage, D.F., Silver, P.A. \& Way, J.C. (2010). Engineering cyanobacteria to synthesize and export hydrophilic products. Appl. Environ. Microbiol. 76, 3462-3466.

Nixon, S.L., Cousins, C.R. \& Cockell, C.S. (2013). Plausible microbial metabolisms on Mars. Astron. Geophys. 54, 13-16.

Olsson-Francis, K. \& Cockell, C.S. (2010). Use of cyanobacteria for in-situ resource use in space applications. Planet. Space Sci. 58, 1279-1285.

Olsson-Francis, K., de la Torre, R., Towner, M.C. \& Cockell, C.S. (2009). Survival of akinetes (resting-state cells of cyanobacteria) in low Earth orbit and simulated extraterrestrial conditions. Orig. Life Evol. Biosph. 39, 565-579.

Olsson-Francis, K., de la Torre, R. \& Cockell, C.S. (2010). Isolation of novel extreme-tolerant cyanobacteria from a rock-dwelling microbial community by using exposure to low Earth orbit. Appl. Environ. Microbiol. 76, 2115-2121.

Olsson-Francis, K., Simpson, A.E., Wolff-Boenisch, D. \& Cockell, C.S. (2012). The effect of rock composition on cyanobacterial weathering of crystalline basalt and rhyolite. Geobiology 10, 434-444.

Patnaik, R., Louie, S., Gavrilovic, V., Perry, K., Stemmer, W.P.C., Ryan, C.M. \& del Cardayré, S. (2002). Genome shuffling of Lactobacillus for improved acid tolerance. Nat. Biotechnol. 20, 707-712.

Paul, J.H., Jeffrey, W.H., David, A.W., Deflaun, M.F. \& Cazares, L.H. (1989). Turnover of extracellular DNA in eutrophic and oligotrophic freshwater environments of southwest Florida. Appl. Environ. Microbiol. $\mathbf{5 5}, 1823-1828$.
Paungfoo-Lonhienne, C., Lonhienne, T.G.A., Rentsch, D., Robinson, N., Christie, M., Webb, R.I., Gamage, H.K., Carroll, B.J., Schenk, P.M. \& Schmidt, S. (2008). Plants can use protein as a nitrogen source without assistance from other organisms. Proc. Natl. Acad. Sci. U.S.A. 105, $4524-4529$.

Pavlov, A.A., Vasilyev, G., Ostryakov, V.M., Pavlov, A.K. \& Mahaffy, P. (2012). Degradation of the organic molecules in the shallow subsurface of Mars due to irradiation by cosmic rays. Geophys. Res. Lett. 39, L13202.

Perchonok, M.H., Cooper, M.R. \& Catauro, P.M. (2012). Mission to Mars: Food Production and Processing for the Final Frontier, NASA Spec. ed, Annual Review of Food Science and Technology. NASA, Lyndon B. Johnson Space Center, Lyndon B. Johnson Space Center, Houston, TX.

Peters, G.A. \& Meeks, J.C. (1989). The Azolla-Anabaena symbiosis: basic biology. Annu. Rev. Plant Physiol. Plant Mol. Biol. 40, 193-210.

Pollard, E.C. (1965). Theoretical studies on living systems in the absence of mechanical stress. J. Theor. Biol. 8, 113-123.

Pollard, E.C. (1967). Physical determinants of receptor mechanisms. In Gravity and the Organism, ed. Gordon, S.A. \& Cohen, M.J., pp. 25-34. The University of Chicago Press, Chicago, IL.

Poughon, L., Farges, B., Dussap, C.G., Godia, F. \& Lasseur, C. (2009). Simulation of the MELiSSA closed loop system as a tool to define its integration strategy. Adv. Space Res. 44, 1392-1403.

Pulz, O. \& Gross, W. (2004). Valuable products from biotechnology of microalgae. Appl. Microbiol. Biotechnol. 65, 635-648.

Qiang, H., Zarmi, Y. \& Richmond, A. (1998). Combined effects of light intensity, light-path and culture density on output rate of Spirulina platensis (Cyanobacteria). Eur. J. Phycol. 33, 165-171.

Qin, L., Qingni, Y., Weidang, A., Yongkang, T., Jin, R. \& Shuangsheng, G. (2014). Response of cyanobacteria to low atmospheric pressure. Life Sci. Space Res. 3, 55-62.

Quintana, N., Van der Kooy, F., Van de Rhee, M.D., Voshol, G.P. \& Verpoorte, R. (2011). Renewable energy from cyanobacteria: energy production optimization by metabolic pathway engineering. Appl. Microbiol. Biotechnol. 91, 471-490.

Rapp, D. (2007). Human Missions to Mars: Enabling Technologies for Exploring the Red Planet. Springer, Heidelberg, New York, Dordrecht and London, and Praxis Publishing Ltd, Chichester, UK.

Rapp, D. (2013). Use of Extraterrestrial Resources for Human Space Missions to Moon or Mars. Springer, Heidelberg, New York, Dordrecht and London, and Praxis Publishing Ltd, Chichester, UK.

Raven, J.A., Wollenweber, B. \& Handley, L.L. (1992). A comparison of ammonium and nitrate as nitrogen sources for photolithotrophs. New Phytol. 121, 19-32.

Rentsch, D., Schmidt, S. \& Tegeder, M. (2007). Transporters for uptake and allocation of organic nitrogen compounds in plants. FEBS Lett. 581, 22812289.

Rieder, R. (1997). The chemical composition of Martian soil and rocks returned by the Mobile Alpha Proton X-ray Spectrometer: preliminary results from the X-ray mode. Science 278, 1771-1774.

Roach, L.H. et al. (2007). CRISM spectral signatures of the north polar gypsum dunes. In Lunar and Planetary Science XXXVIII, LPI Contribution No. 1338, League City, TX, id. 1970.

Rothschild, L.J. (2010). A powerful toolkit for synthetic biology: over 3.8 billion years of evolution. Bioessays 32, 304-313.

Rothschild, L.J. \& Mancinelli, R.L. (2001). Life in extreme environments. Nature 409, 1092-1101.

Salisbury, F., Gitelson, J. \& Lisovsky, G. (1997). Bios-3: Siberian experiments in bioregenerative life support. Bioscience 47, 575-585.

Scalzi, G., Selbmann, L., Zucconi, L., Rabbow, E., Horneck, G., Albertano, P. \& Onofri, S. (2012). LIFE experiment: isolation of cryptoendolithic organisms from Antarctic colonized sandstone exposed to space and simulated Mars conditions on the International Space Station. Orig. Life Evol. Biosph. 42, 253-262.

Schirmack, J., Böhm, M., Brauer, C., Löhmannsröben, H.-G., de Vera, J.-P., Möhlmann, D. \& Wagner, D. (2014). Laser spectroscopic real time measurements of methanogenic activity under simulated Martian subsurface analog conditions. Planet. Space Sci. 98, 198-204. 
Schneegurt, M.A. \& Sherman, L.A. (1996). A role for the diazotrophic cyanobacterium, Cyanothece sp. strain ATCC 51142, in nitrogen cycling for CELSS applications. Life Support Biosph. Sci. 3, 47-52.

Schneegurt, M.A., Arieli, B., McKeehen, J.D., Stephens, S.D., Nielsen, S.S., Saha, P.R., Trumbo, P.R. \& Sherman, L.A. (1995). Compositional and toxicological evaluation of the diazotrophic cyanobacterium, Cyanothece sp. strain ATCC 51142. Aquaculture 134, 339-349.

Schneegurt, M.A., Arieli, B., Nielsen, S.S., Trumbo, P.R. \& Sherman, L.A. (1996). Evaluation of Cyanothece sp. ATCC 51142 as a candidate for inclusion in a CELSS. Adv. Space Res. 18, 177-180.

Schneider, M.A. \& Bruckner, A.P. (2003). Extraction of water from the Martian atmosphere. In Space Technology and Applications International Forum - STAIF 2003, ed. El-Gen, M.S., pp. 1124-1132. American Institute of Physics, Melville, NY.

Schuerger, A.C., Mancinelli, R.L., Kern, R.G., Rothschild, L.J. \& McKay, C.P. (2003). Survival of endospores of Bacillus subtilis on spacecraft surfaces under simulated Martian environments: implications for the forward contamination of Mars. Icarus 165, 253-276.

Schuerger, A.C., Ulrich, R., Berry, B.J. \& Nicholson, W.L. (2013). Growth of Serratia liquefaciens under $7 \mathrm{mbar}, 0^{\circ} \mathrm{C}$, and $\mathrm{CO}_{2}$-enriched anoxic atmospheres. Astrobiology 13, 115-131.

Sezonov, G., Joseleau-Petit, D. \& D'ari, R. (2007). Escherichia coli physiology in Luria-Bertani broth. J. Bacteriol. 189, 8746-8749.

Shields, L.M., Durrell, L.W. \& Sparrow, A.H. (1961). Preliminary observations on radio-sensitivity of algae and fungi from soils of the Nevada test site. Ecology 42, 440-441.

Shiloach, J. \& Fass, R. (2005). Growing E. coli to high cell density - a historical perspective on method development. Biotechnol. Adv. 23, 345-357.

Silverstone, S.E. \& Nelson, M. (1996). Food production and nutrition in Biosphere 2: results from the first mission September 1991 to September 1993. Adv. Space Res. 18, 49-61.

Silverstone, S., Nelson, M., Alling, A. \& Allen, J. (2003). Development and research program for a soil-based bioregenerative agriculture system to feed a four person crew at a Mars base. Adv. Space Res. 31, 69-75.

Silverstone, S., Nelson, M., Alling, A. \& Allen, J.P. (2005). Soil and crop management experiments in the Laboratory Biosphere: an analogue system for the Mars on Earth $^{\circledR}$ facility. Adv. Space Res. 35, 1544-1551.

Singh, S. (2014). A review on possible elicitor molecules of cyanobacteria: their role in improving plant growth and providing tolerance against biotic or abiotic stress. J. Appl. Microbiol. 117, 1221-1244.

Singh, H., Anurag, K. \& Apte, S.K. (2013). High radiation and desiccation tolerance of nitrogen-fixing cultures of the cyanobacterium Anabaena sp. Strain PCC 7120 emanates from genome/proteome repair capabilities. Photosynth. Res. 118, 71-81.

Singh, H., Fernandes, T. \& Apte, S.K. (2010). Unusual radioresistance of nitrogen-fixing cultures of Anabaena strains. J. Biosci., 35, 427-434.

Slade, D. \& Radman, M. (2011). Oxidative stress resistance in Deinococcus radiodurans. Microbiol. Mol. Biol. Rev. 75, 133-191.

Spiller, H. \& Gunasekaran, M. (1990). Ammonia-excreting mutant strain of the cyanobacterium Anabaena variabilis supports growth of wheat. Appl. Environ. Microbiol. 33, 447-480.

Spiller, H., Latorre, C., Hassan, M.E. \& Shanmugam, K.T. (1986). Isolation and characterization of nitrogenase-derepressed mutant strains of cyanobacterium Anabaena variabilis. J. Bacteriol. 165, 412-419.

Squyres, S.W. et al. (2012). Ancient impact and aqueous processes at Endeavour Crater, Mars. Science 336, 570-576.

Stanford-Brown 2011 iGEM Team (2011). PowerCell (Introduction). http://2011.igem.org/Team:Brown-Stanford/PowerCell/Introduction (accessed 8 June 2014).

Stevenson, B. \& Waterbury, J. (2006). Isolation and identification of an epibiotic bacterium associated with heterocystous Anabaena cells. Biol. Bull. 210, 73-77.

Stoker, C.R., Gooding, J.L., Roush, T., Banin, A., Burt, D., Clark, B.C., Flynn, G. \& Gwynne, O. (1993). The physical and chemical properties and resource potentials of Martian surface soils. In Resources of Near Earth Space, ed. Lewis, J.S., Matthews, M.S. \& Guerrieri, M.L., pp. 659-707. The Arizona Board of Regents, Tucson, AZ.
Subramanian, G. \& Shanmugasundaram, S. (1986). Uninduced ammonia release by the nitrogen-fixing cyanobacterium Anabaena. FEMS Microbiol. Lett. 37, 151-154.

Sychev, V.N., Shepelev, E.Y., Meleshko, G.I., Gurieva, T.S., Levinskikh, M.A., Podolsky, I.G., Dadasheva, O.A. \& Popov, V.V. (2001). Main characteristics of biological components of developing life support system observed during the experiments aboard orbital complex MIR. Adv. Space Res. 27, 1529-1534.

Sychev, V.N., Levinskikh, M.A. \& Shepelev, Y.Y. (2003). The biological component of the life support system for a Martian expedition. $A d v$. Space Res. 31, 1693-1698.

Takahama, K., Matsuoka, M., Nagahama, K. \& Ogawa, T. (2003). Construction and analysis of a recombinant cyanobacterium expressing a chromosomally inserted gene for an ethylene-forming enzyme at the psbAI locus. J. Biosci. Bioeng. 95, 302-305.

Takahama, K., Matsuoka, M., Nagahama, K. \& Ogawa, T. (2004). High-frequency gene replacement in cyanobacteria using a heterologous rps12 gene. Plant Cell Physiol. 45, 333-339.

Taylor, S.R. \& McLennan, S.M. (2009). Planetary Crusts: Their Composition, Origin and Evolution, Moon. Cambridge University Press, Cambridge.

Thomas, D., Sullivan, S., Sprice, A. \& Zimmerman, S. (2005). Common freshwater cyanobacteria grow in $100 \% \mathrm{CO}_{2}$. Astrobiology 5, 66-74.

Thomas, D.J., Boling, J., Boston, P.J., Campbell, K.A., McSpadden, T., McWilliams, L. \& Todd, P. (2006). Extremophiles for ecopoiesis: desirable traits for and survivability of pioneer Martian organisms. Gravit. Space Biol. 19, 91-104.

Trautmann, D., Voß, B., Wilde, A., Al-Babili, S. \& Hess, W.R. (2012). Microevolution in cyanobacteria: re-sequencing a motile substrain of Synechocystis sp. PCC 6803. DNA Res. 19, 435-448.

Tikhomirov, A.A., Ushakova, S.A., Kovaleva, N.P., Lamaze, B., Lobo, M. \& Lasseur, C. (2007). Biological life support systems for a Mars mission planetary base: problems and prospects. Adv. Space Res. 40, 1741-1745.

Tokano, T. (ed.) (2005). Water on Mars and Life. Springer, Berlin.

Tokusoglu, Ö. \& Unal, M.K. (2003). Biomass nutrient profiles of three microalgae: Spirulina platensis, Chlorella vulgaris and Isochrysis galbana. J. Food Sci. 68, 1144-1148.

Toprak, E., Veres, A., Yildiz, S. \& Pedraza, J. (2013). Building a morbidostat: an automated continuous-culture device for studying bacterial drug resistance under dynamically sustained drug inhibition. Nat. Protoc. 8, $555-567$.

Vaniman, D.T. et al. (2014). Mineralogy of a mudstone at Yellowknife Bay, Gale crater, Mars. Science 343, 1243480.

Verseux, C., Paulino-Lima, I.G., Baqué, M., Rothschild, L.J. \& Billi, D. (2016). Synthetic biology for space exploration: promises and societal implications. In Ambivalences of Creating Life. Societal and Philosophical dimensions of Synthetic Biology, ed. Hagen, K., Engelhard, M. \& Toepfer, G., Springer-Verlag, Berlin and Heidelberg.

Wainwright, M., Wickramasinghe, N.C., Narlikar, J.V. \& Rajaratnam, P. (2003). Microorganisms cultured from stratospheric air samples obtained at $41 \mathrm{~km}$. FEMS Microbiol. Lett. 218, 161-165.

Wamelink, G.W.W., Frissel, J.Y., Krijnen, W.H.J., Verwoert, M.R. \& Goedhart, P.W. (2014). Can plants grow on Mars and the moon: a growth experiment on Mars and moon soil simulants. PLOS ONE 9, e103138.

Wang, B., Wang, J., Zhang, W. \& Meldrum, D.R. (2012). Application of synthetic biology in cyanobacteria and algae. Front. Microbiol. 3, 344.

Wang, G., Li, G., Li, D., Liu, Y., Song, L., Tong, G., Liu, X. \& Cheng, E. (2004). Real-time studies on microalgae under microgravity. Acta Astronaut. 55, 131-137.

Wang, G., Chen, H., Li, G., Chen, L., Li, D., Hu, C., Chen, K. \& Liu, Y. (2006). Population growth and physiological characteristics of microalgae in a miniaturized bioreactor during space flight. Acta Astronaut. 58, 264-269.

Wang, H.H., Isaacs, F.J., Carr, P.A., Sun, Z.Z., Xu, G., Forest, C.R. \& Church, G.M. (2009). Programming cells by multiplex genome engineering and accelerated evolution. Nature 460, 894-898. 
Warren-Rhodes, K.A., Rhodes, K.L., Pointing, S.B., Ewing, S.A., Lacap, D.C., Gómez-Silva, B., Amundson, R., Friedmann, E.I. \& McKay, C.P. (2006). Hypolithic cyanobacteria, dry limit of photosynthesis, and microbial ecology in the hyperarid Atacama Desert. Microb. Ecol. 52, 389-398.

Wassmann, M., Moeller, R., Reitz, G. \& Rettberg, P. (2010). Adaptation of Bacillus subtilis cells to Archean-like UV climate: relevant hints of microbial evolution to remarkably increased radiation resistance. Astrobiology 10, 605-615.

Way, J.C., Silver, P.A. \& Howard, R.J. (2011). Sun-driven microbial synthesis of chemicals in space. Int. J. Astrobiol. 10, 359-364.

Wheeler, R.M. (2004). Horticuture for Mars. In ISHS Acta Horticulturae 642 , ed. Looney, N.E., pp. 201-15. ISHS, Toronto, Canada.

Wiens, J., Bommarito, F., Blumenstein, E., Ellsworth, M., Cisar, T., McKinney, B. \& Knecht, B. (2001). Water extraction from Martian soil. In Fourth Annual HEDS-UP Forum, LPI Contribution No. 1106, Houston, TX.

Wierzchos, J., Ascaso, C. \& McKay, C.P. (2006). Endolithic cyanobacteria in halite rocks from the hyperarid core of the Atacama Desert. Astrobiology 6, 415-422.

Wijffels, R.H., Kruse, O. \& Hellingwerf, K.J. (2013). Potential of industrial biotechnology with cyanobacteria and eukaryotic microalgae. Curr. Opin. Biotechnol. 24, 405-413.

Williams, J.D., Coons, S.C. \& Bruckner, A.P. (1995). Design of a water vapor adsorption reactor for Martian in situ resource utilization. $J$. Br. Interplanet. Soc. 48, 347-354.

Wilson, J.W. et al. (2007). Space flight alters bacterial gene expression and virulence and reveals a role for global regulator Hfq. Proc. Natl. Acad. Sci. U.S.A. 104, 16299-16304.
Xiao, Y., Liu, Y., Wang, G., Hao, Z. \& An, Y. (2010). Simulated microgravity alters growth and microcystin production in Microcystis aeruginosa (cyanophyta). Toxicon 56, 1-7.

Yang, C., Liu, H., Li, M., Yu, C. \& Yu, G. (2008). Treating urine by Spirulina platensis. Acta Astronaut. 63, 1049-1054.

Zaets, I., Burlak, O., Rogutskyy, I., Vasilenko, A., Mytrokhyn, O., Lukashov, D., Foing, B. \& Kozyrovska, N. (2011). Bioaugmentation in growing plants for lunar bases. Adv. Space Res. 47, 1071-1078.

Zhou, Y., Zhang, Y., Wang, X., Cui, J., Xia, X., Shi, K. \& Yu, J. (2011). Effects of nitrogen form on growth, $\mathrm{CO}$ assimilation, chlorophyll fluorescence, and photosynthetic electron allocation in cucumber and rice plants. J. Zhejiang Univ. B 12, 126-134.

Zhukov-Verezhnikov, N.N. et al. (1962). Results of first microbiological and cytological experiments on Earth satellites in space. Artif. Earth Satell. 11, 47-71.

Zisk, S.H. \& Mouginis-Mark, P.J. (1980). Anomalous region on Mars implications for near-surface liquid water. Nature 288, 126-129.

Zubrin, R. \& Wagner, R. (2011). The Case for Mars: The Plan to Settle the Red Planet and Why We Must, 2011 edn. Free Press, New York.

Zubrin, R., Brian, F. \& Tomoko, K. (1997). Mars in-situ resource utilization based on the reverse water gas shift - experiments and mission applications. In 33rd Joint Propulsion Conf. and Exhibit, Seattle, WA, AIAA 97-2767.

Zubrin, R.M., Baker, D.A. \& Gwynne, O. (1991). Mars Direct: a simple, robust, and cost effective architecture for the space exploration initiative. In 29th Aerospace Sciences Meeting, Reno, NV, AIAA 910329. 